Article

\title{
New Analytical Solutions for Longitudinal Vibration of a Floating Pile in Layered Soils with Radial Heterogeneity
}

\author{
Zhimeng Liang ${ }^{1}$, Chunyi Cui ${ }^{1, *}$, Kun Meng ${ }^{1,2}$, Yu Xin ${ }^{1}$, Huafu Pei ${ }^{3}$ and Haijiang Li ${ }^{2}$ \\ 1 Department of Civil Engineering, Dalian Maritime University, Dalian 116026, China; \\ liangzhimeng@dlmu.edu.cn (Z.L.); mengkuntumu@dlmu.edu.cn (K.M.); sdxinyu@dlmu.edu.cn (Y.X.) \\ 2 Cardiff School of Engineering, Cardiff University, Queen's Buildings, The Parade, Cardiff, Wales CF24 3AA, \\ UK; LiH@cardiff.ac.uk \\ 3 Faculty of Infrastructure Engineering, Dalian University of Technology, Dalian 116024, China; \\ huafupei@dlut.edu.cn \\ * Correspondence: cuichunyi@dlmu.edu.cn; Tel.: +86-411-84723186
}

Received: 17 July 2020; Accepted: 31 July 2020; Published: 5 August 2020

\begin{abstract}
Based on the theory of wave propagation in three-dimensional (3D) continuum, a new analytical approach for the longitudinal vibration characteristics of a floating pile in layered soils with radial heterogeneity is developed by employing a viscous-type damping model. Firstly, an analytical solution for the longitudinal complex impedance at the pile head is deduced by employing the Laplace transform and complex stiffness technique with the compatibility conditions of the pile and radially inhomogeneous surrounding soil. Secondly, a semi-analytical solution in the time domain is further acquired by using the inverse Fourier transform method. Furthermore, the corresponding analytical solutions are validated through contrasts with previous solutions. Finally, parametric analyses are underway to investigate the effect of radial heterogeneity of surrounding soils on longitudinal vibration characteristics of floating piles. It is indicated that the proposed approach and corresponding solutions can provide a more wide-ranging application than the simple harmonic vibration for longitudinal vibration analysis of a floating pile in soils.
\end{abstract}

Keywords: pile vibration; analytical approach; longitudinal complex impedance; velocity admittance; radial heterogeneity; viscous-type damping

\section{Introduction}

Structures such as bridges, tall buildings, and offshore platform often have piles as foundations that experience dynamic loads from traffic, earthquakes, and mechanical oscillations. The dynamic response of pile-soil interactions has always been a hot topic in research fields of geotechnical engineering and soil dynamics; it has great reference value and guidance for pile dynamic detection, earthquake-resistance design, and dynamic foundation design [1-3]. Many approaches for the dynamic interaction systems of pile-soil vibration have been proposed by many scholars in which the soil is commonly considered to be radially homogeneous [4-9]. The Winkler model has been widely used due to its convenience, considering the surrounding soil as a series of spring-dashpot elements [10]. Nevertheless, the wave propagation within the soil around the pile is completely ignored in the Winkler model [11,12]. Novak and Nogami [13] further presented a plane-strain model by assuming the surrounding soils as thin visco-elastic layers with hysteretic-type damping. Manna and Baidya [14] found the performance of the Novak's model was unsatisfactory in a certain high-frequency range for neglecting the longitudinal wave propagation between thin layers. Subsequently, various simplified models for pile vibration were proposed to consider the effect of 3D wave propagation within surrounding soil $[15,16]$. Furthermore, 
Zheng et al. [17], Cai et al. [18], Yang et al. [19], and Cui et al. [20,21] examined the dynamic behavior of foundations (e.g., piles and plates) in a saturated mediu under longitudinal excitation by regarding the soil layer as porous saturated media.

However, there still exist some physical reactions occurring naturally in the disturbed environment [22-24]. When the construction operations cause soil disturbance within the vicinity of the pile shaft, the influence of soil radial inhomogeneity on the characteristics of pile-soil systems should not be ignored [25]. Novak and Sheta [26] developed a simple massless boundary zone model to take the radial heterogeneity of surrounding soil into account. Subsequently, Veletsos and Dotson [27] proposed a new model by dividing the surrounding soil into two layers, a semi-infinite outer undisturbed zone and an inner disturbed zone. To eliminate wave reflection at the interface of the boundary zone, Han and Sabin [28] presented a mechanical model of softening the boundary region without reflective phenomenon, in which the shear modulus and material damping are described as a change in the parabola. Furthermore, EI Naggar [29] employed annular sub-layers to examine the strengthened effect of surrounding soil on the longitudinal complex impedance of the soil layer. Moreover, the research team of Wang [30,31] pointed out the defects of EI Naggar's model and then presented a new method for the longitudinal vibration of the pile-soil interaction system by utilizing the complex stiffness method in the hysteretic-damping soil. Afterwards, based on Wang's model, $\mathrm{Li}$ et al. [32] developed a new method to research the longitudinal vibration characteristics of a large-diameter pile in radially heterogeneous media.

Significantly, most of above mentioned research adopted hysteretic-type damping to describe the material damping, which is only satisfactory for harmonic excitation and is independent of the frequency [33]. On the contrary, viscous-type damping is appropriate for pile vibration which is subjected to a non-harmonic excitation load [34]. Therefore, Cui et al. [35] developed a new method for the longitudinal response of a pipe pile embedded in radially heterogeneous media with a viscous-type damping model.

To date, based on the theory of 3D wave propagation and the viscous-type damping model, there is little work on the longitudinal vibration of piles embedded in radially heterogeneous media. In this paper, a new analytical approach for the longitudinal vibration of a floating pile embedded in bidirectional heterogeneous soil with a viscous-type damping model is proposed, by extending the complex stiffness transfer method, inverse Fourier transform, and the theory of 3D wave propagation in continuum. Extensive parametric analyses were also conducted to study the longitudinal vibration characteristics of a floating pile in longitudinally layered soils with radial heterogeneity. The proposed model can simulate the complicated working conditions better than the homogeneous media in the subgrade and can provide a reference and guide for practical engineering.

\section{Simplified Mechanical Model and Basic Assumptions}

Figure 1 depicts a new simplified computational model of the coupled system of pile and soil. This interaction system is divided into $m$ layers and segments in a longitudinal direction, of the surrounding soil and pile shaft, respectively, numbered $1,2, \ldots, i, \ldots, m$. The thickness and the upper interface depth of the $i$ th soil layer are $l_{i}$ and $h_{i}$, respectively. $r_{i 1}$ and $r_{i\left(m^{\prime}+1\right)}$ are the radii of the $i$ th pile segment and disturbed zone, respectively, of the $i$ th soil layer. The $i$ th soil layer with radial thickness $b_{i}$ is further subdivided into $m^{\prime}$ radial sub-layers, ordered $1,2, \ldots, j, \ldots, m^{\prime} . r_{i j}$ represents the radius of the inner interface for the $j$ th subzone within the $i$ th vertical soil layer. $G_{i j}^{S}(r)$ and $c_{i j}^{S}(r)$ are the shear modulus and viscous damping coefficient, respectively, which satisfy the following expressions:

$$
G_{i j}^{S}(r)=\left\{\begin{array}{cc}
G_{i 1}^{S} & \multicolumn{1}{c}{r=r_{i 1}} \\
G_{i\left(m^{\prime}+1\right)}^{S} \times f_{i}(r) & r_{i 1}<r<r_{i\left(m^{\prime}+1\right)} \\
G_{i\left(m^{\prime}+1\right)}^{S} & r \geq r_{i\left(m^{\prime}+1\right)}
\end{array}\right.
$$




$$
c_{i j}^{S}(r)=\left\{\begin{array}{cc}
c_{i 1}^{S} & r=r_{i 1} \\
c_{i\left(m^{\prime}+1\right)}^{S} \times f_{i}(r) & r_{i 1}<r<r_{i\left(m^{\prime}+1\right)} \\
c_{i\left(m^{\prime}+1\right)}^{S} & r \geq r_{i\left(m^{\prime}+1\right)}
\end{array}\right.
$$

where $f_{i}(r)$ is a parabolic function [31]. The shear modulus and viscous damping coefficient of each radial sub-zone which is homogeneous inside, are determined by Equations (1) and (2) with respect to the corresponding radius $r_{i j}$. The interaction between the interfaces of longitudinal layers is assumed to follow the Kelvin-Voigt model. $k_{i j}^{S}$ and $\delta_{i j}^{S}$ are visco-elastic constants of the Kelvin-Voigt model at the interface between the $i$ th and $(i-1)$ th layers, of the $j$ th sub-zone. Similarly, the corresponding constants of visco-elastic supports beneath the pile toe are $\delta_{\mathrm{p}}$ and $k_{\mathrm{p}} \cdot p(t)$ denotes the uniformly distributed excitation load.

In this paper, some assumptions are given in the presented mechanical model:

(1) The soil around the pile consists of two zones, one is a semi-infinite area, the other is an inner disturbed area.

(2) The inner disturbed zone is subdivided into a series of annular sub-zones, and each annular region is deemed to be homogeneous, linear viscoelastic, and isotropic [30,31].

(3) The displacement and shear stress at the interface between neighboring annular sub-zones are continuous.

(4) The surrounding soils are linear visco-elastic continuums with frequency-dependent viscous-type damping [36].

(5) The deformations of the soil-pile system are small. There is no interface sliding between the pile and soils.

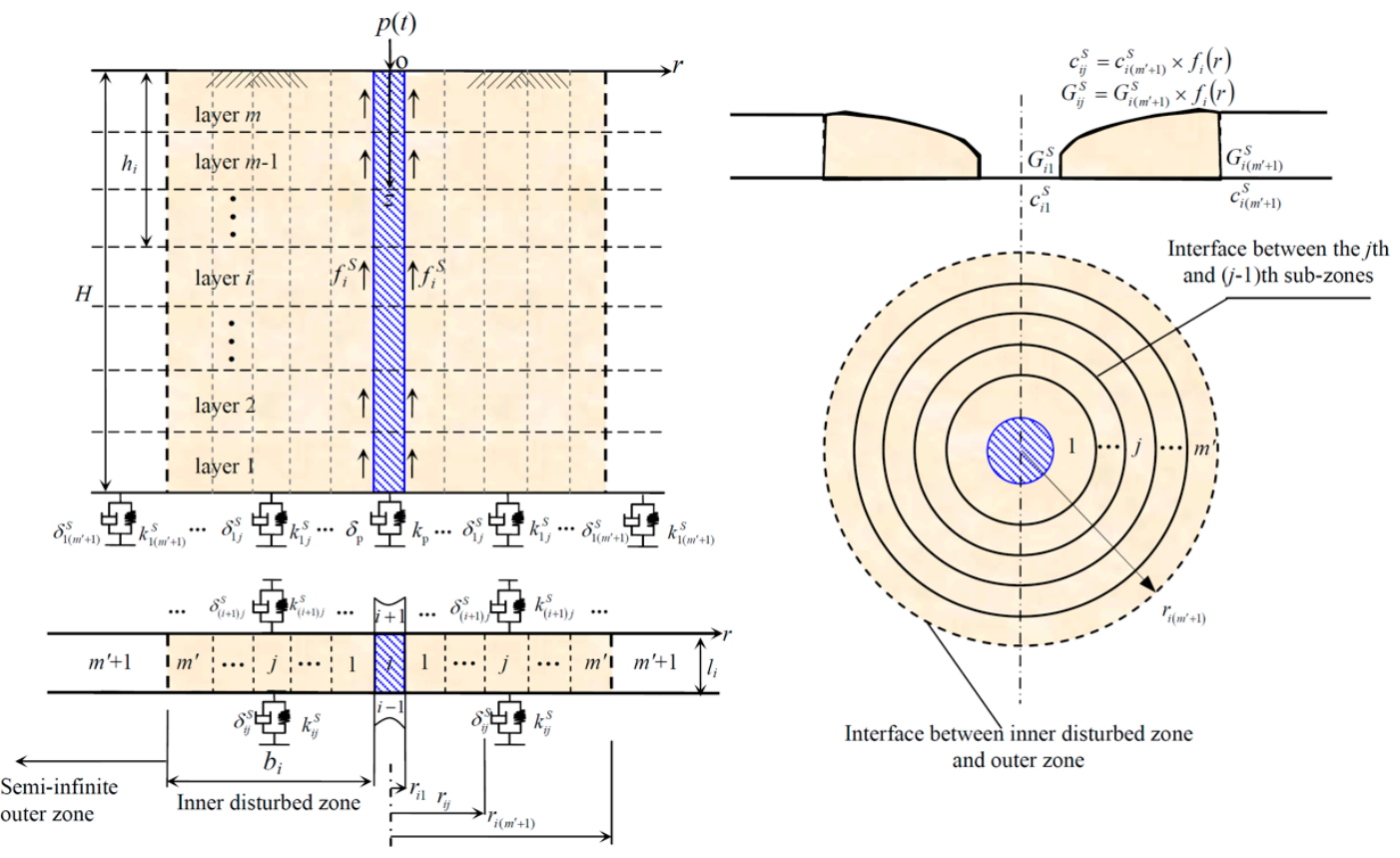

Figure 1. The simplified mechanical model.

\section{Governing Equations}

According to the elastodynamic theory of 3D continuums, the governing equation of the $j$ th surrounding soil in the axisymmetric conditions is established as follows:

$$
\left(\lambda_{i j}^{S}+2 G_{i j}^{S}\right) \frac{\partial^{2}}{\partial z^{2}} u_{i j}^{S}(r, z, t)+G_{i j}^{S}\left(\frac{1}{r} \frac{\partial}{\partial r}+\frac{\partial^{2}}{\partial r^{2}}\right) u_{i j}^{S}(r, z, t)+c_{i j}^{S} \frac{\partial}{\partial t}\left[\left(\frac{\partial^{2}}{\partial r^{2}}+\frac{1}{r} \frac{\partial}{\partial r}+\frac{\partial^{2}}{\partial z^{2}}\right) u_{i j}^{S}(r, z, t)\right]=\rho_{i j}^{S} \frac{\partial^{2}}{\partial t^{2}} u_{i j}^{S}(r, z, t)
$$


where $u_{i j}^{S}(r, z, t), \rho_{i j^{\prime}}^{S} \lambda_{i j}^{S}, G_{i j^{\prime}}^{S}, c_{i j^{\prime}}^{S} \mu_{i j}^{S}$ are the longitudinal displacement, density, Lame's constant, shear modulus, viscous damping coefficient, and Poisson's ratio, respectively; $\lambda_{i j}^{S}=2 G_{i j}^{S} \mu_{i j}^{S} /\left(1-2 \mu_{i j}^{S}\right)$.

The longitudinal shear stress at the interface between the first radial sub-zone and pile segment is

$$
\tau_{i 1}^{S}(r, z, t)=G_{i 1}^{S} \frac{\partial u_{1}^{S}(r, z, t)}{\partial r}+c_{i 1}^{S} \frac{\partial^{2} u_{i 1}^{S}(r, z, t)}{\partial t \partial r}
$$

The vibration behavior of the $i$ th pile segment can be written by

$$
E_{i}^{P} A_{i}^{P} \frac{\partial^{2} u_{i}^{P}(z, t)}{\partial z^{2}}-m_{i}^{P} \frac{\partial^{2} u_{i}^{P}(z, t)}{\partial t^{2}}-2 \pi r_{i 1} f_{i}^{S}(z, t)=0
$$

where $E_{i}^{p}$ and $A_{i}^{p}$ denote the elastic modulus and cross-section area, respectively; the shear stress at the interface between the first radial sub-zone of soil and the $i$ th pile segment $f_{i}^{S}(z, t)$ satisfies $f_{i}^{S}(z, t)=\left.\tau_{i 1}^{S}(r, z, t)\right|_{r=r_{i 1}} ; m_{i}^{P}=\rho_{i}^{P} A_{i}^{P}, A_{i}^{P}=\pi r_{i 1}^{2}$.

\section{Boundary and Initial Conditions}

The boundary condition at the interface between the $i$ th and $(i+1)$ th vertical layers of the $j$ th radial sub-zone can be given by

$$
\left.\frac{\partial u_{i j}^{S}(r, z, t)}{\partial z}\right|_{z=h_{i}}=-\left[\frac{\delta_{(i+1) j}^{S}}{E_{i j}^{S}} \frac{\partial u_{i j}^{S}(r, z, t)}{\partial t}+\frac{k_{(i+1) j}^{S}}{E_{i j}^{S}} u_{i j}^{S}(r, z, t)\right]
$$

where $E_{i j}^{S}$ is Young's modulus.

The boundary condition at the lower interface of $i$ th vertical layers, within the $j$ th radial sub-zone, can be given by

$$
\left.\frac{\partial u_{i j}^{S}(r, z, t)}{\partial z}\right|_{z=h_{i}+l_{i}}=-\left[\frac{k_{i j}^{S} u_{i j}^{S}(r, z, t)}{E_{i j}^{S}}+\frac{\delta_{i j}^{S}}{E_{i j}^{S}} \frac{\partial u_{i j}^{S}(r, z, t)}{\partial t}\right]
$$

For the $i$ th vertical layer of soil, the completely coupled conditions are:

$$
\begin{gathered}
G_{i j}^{S} \frac{\partial u_{i j}^{S}}{\partial r}+\left.c_{i j}^{S} \frac{\partial^{2} u_{i j}^{S}}{\partial t \partial r}\right|_{r=r_{i(j+1)}}=G_{i(j+1)}^{S} \frac{\partial u_{i(j+1)}^{S}}{\partial r}+\left.c_{i(j+1)}^{S} \frac{\partial^{2} u_{i(j+1)}^{S}}{\partial t \partial r}\right|_{r=r_{i(j+1)}} \\
\left.u_{i j}^{S}(r, z, t)\right|_{r=r_{i(j+1)}}=\left.u_{i(j+1)}^{S}(r, z, t)\right|_{r=r_{i(j+1)}}
\end{gathered}
$$

The completely coupled conditions at the interface between the $i$ th pile segment and the first radial sub-zone of the $i$ th vertical layer are:

$$
\begin{aligned}
& \left.u_{i 1}^{S}(r, z, t)\right|_{r=r_{i 1}}=u_{i}^{P}(z, t) \\
& f_{i}^{S}(z, t)=\left.\tau_{i 1}^{S}(r, z, t)\right|_{r=r_{i 1}}
\end{aligned}
$$

The fringe conditions of the $i$ th pile segment satisfy the following expressions.

$$
\begin{gathered}
\left.\frac{d u_{i}^{P}}{d z}\right|_{z=h_{i}}=-\frac{z_{i}^{P} u_{i}^{P}}{E_{i}^{P} A_{i}^{P}} \\
\left.\frac{d u_{i}^{P}}{d z}\right|_{z=h_{i}+l_{i}}=-\frac{z_{i-1}^{P} u_{i}^{P}}{E_{i}^{P} A_{i}^{P}}
\end{gathered}
$$


where $z_{i-1}^{P}$ and $z_{i}^{P}$ are the displacement impedance functions at the top and toe of the ith pile segment, respectively.

\section{Solution of the Governing Soil}

The derivation procedure of the analytical solution is shown in Figure 2.

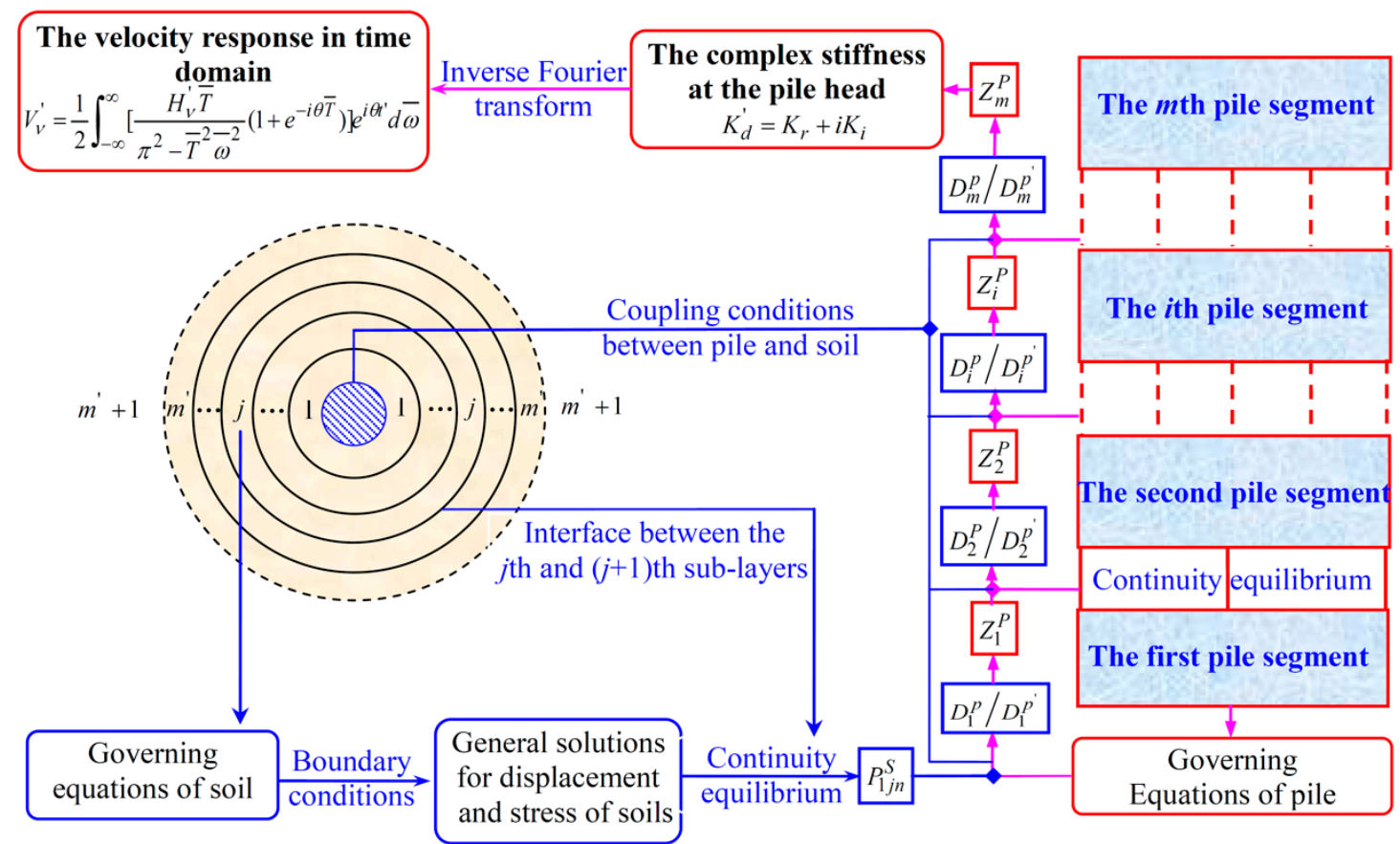

Figure 2. The derivation procedure of the analytical solution.

Taking the Laplace transform, Equation (4) can be rewritten as

$$
\left(\lambda_{i j}^{S}+2 G_{i j}^{S}\right) \frac{\partial^{2}}{\partial z^{2}} U_{i j}^{S}(r, z, s)+G_{i j}^{S}\left(\frac{1}{r} \frac{\partial}{\partial r}+\frac{\partial^{2}}{\partial r^{2}}\right) U_{i j}^{S}(r, z, s)+c_{i j}^{S} s\left(\frac{\partial^{2}}{\partial r^{2}}+\frac{1}{r} \frac{\partial}{\partial r}+\frac{\partial^{2}}{\partial z^{2}}\right) U_{i j}^{S}(r, z, s)=\rho_{i j}^{S} s^{2} U_{i j}^{S}(r, z, s)
$$

where $s=i \omega, i=\sqrt{-1}, U_{i j}^{S}$ is the Laplace transform of $u_{i j}^{S}$.

Applying the separation variable method, the displacement of the $j$ th radial sub-zone within the first vertical layer can be viewed in Appendix A.

Thus, the shear stress at the inner interface of the $j$ th radial sub-zone within the first vertical layer yields:

$$
\tau_{1 j}^{S}=\left\{\begin{array}{l}
\left(G_{1 j}^{S}+c_{1 j}^{S} s\right) \sum_{n=1}^{\infty} A_{1 j n}^{S} q_{1 j n}^{S} K_{1}\left(q_{1 j n}^{S} r\right) \cos \left(h_{1 j n}^{S} z^{\prime}-\varphi_{1 j n}^{S}\right) \quad\left(j=m^{\prime}+1\right) \\
\left(G_{1 j}^{S}+c_{1 j}^{S} S\right) \sum_{n=1}^{\infty} q_{1 j n}^{S}\left[-B_{1 j n}^{S} I_{1}\left(q_{1 j n}^{S} r\right)+C_{1 j n}^{S} K_{1}\left(q_{1 j n}^{S} r\right)\right] \cos \left(h_{1 j n}^{S} z^{\prime}-\varphi_{1 j n}^{S}\right) \quad\left(j=m^{\prime}, \ldots, 2,1\right)
\end{array}\right.
$$

where $I_{1}\left(q_{1 j n}^{S} r\right)$ represents modified Bessel functions of the first kind of order one; $K_{1}\left(q_{1 j n}^{S} r\right)$ represents modified Bessel functions of the second kind of order one.

Considering the boundary conditions listed in Equations (8) and (9), we have:

if $j=m^{\prime}$ : 


$$
\begin{aligned}
& \left(G_{1 m^{\prime}}^{S}+c_{1 m^{\prime}}^{S} s\right) q_{1 m^{\prime} n}^{S} K_{1}\left(q_{1 m^{\prime} n}^{S} r_{1\left(m^{\prime}+1\right)}\right) K_{0}\left(q_{1\left(m^{\prime}+1\right) n}^{S} r_{1\left(m^{\prime}+1\right)}\right)-\left(G_{1\left(m^{\prime}+1\right)}^{S}\right. \\
P_{1 m^{\prime} n}^{S}= & \frac{\left.+c_{1\left(m^{\prime}+1\right)}^{S} S\right) K_{0}\left(q_{1 m^{\prime} n}^{S} r_{1\left(m^{\prime}+1\right)}\right) K_{1}\left(q_{1\left(m^{\prime}+1\right) n}^{S} r_{1\left(m^{\prime}+1\right)}\right)}{\left(G_{1 m^{\prime}}^{S}+c_{1 m^{\prime}}^{S} s\right) q_{1 m^{\prime} n}^{S} I_{1}\left(q_{1 m^{\prime} n}^{S} r_{1\left(m^{\prime}+1\right)}\right) K_{0}\left(q_{1\left(m^{\prime}+1\right) n}^{S} r_{1\left(m^{\prime}+1\right)}{ }^{S}\right)+\left(G_{1\left(m^{\prime}+1\right)}^{S}\right.} \\
& \left.+c_{1\left(m^{\prime}+1\right)}^{S} S\right) q_{1\left(m^{\prime}+1\right) n}^{S} I_{0}\left(q_{1 m^{\prime} n}^{S} r_{1\left(m^{\prime}+1\right)}\right) K_{1}\left(q_{1\left(m^{\prime}+1\right) n}^{S} r_{1\left(m^{\prime}+1\right)}\right)
\end{aligned}
$$

if $j=m^{\prime}-1, \ldots, 2,1$ :

$$
\begin{aligned}
P_{1 j n}^{S}= & \frac{-\left(G_{1(j+1)}^{S}+c_{1(j+1)}^{S} S\right) q_{1(j+1) n}^{S} K_{0}\left(q_{j n}^{S} r_{j}\right) \times\left[P_{1(j+1) n}^{S} I_{1}\left(q_{1(j+1) n}^{S} r_{1(j+1)}\right)-K_{1}\left(q_{1(j+1) n}^{S} r_{1(j+1)}\right)\right]}{\left(G_{1 j}^{S}+c_{1 j}^{S} s\right) q_{1 j n}^{S} I_{1}\left(q_{1 j n}^{S} r_{1(j+1)}\right)\left[P_{1(j+1) n}^{S} I_{0}\left(q_{1(j+1) n}^{S} r_{1(j+1)}\right)+K_{0}\left(q_{1(j+1) n}^{S} r_{1(j+1)}\right)\right]-\left(G_{1(j+1)}^{S}\right.} \\
& \left.+\left[-K_{1}\left(q_{1(j+1) n}^{S} r_{1(j+1)}\right)+P_{1(j+1) n}^{S} I_{1}\left(q_{1(j+1) n}^{S} r_{1(j+1)}\right)\right] \times c_{1(j+1)}^{S} S\right) q_{1(j+1) n}^{S} I_{0}\left(q_{1 j n}^{S} r_{1(j+1)}\right)
\end{aligned}
$$

Substituting Equation (15) into Equation (5) and taking the Laplace transform produces

$$
\left(V_{1}^{P}\right)^{2} \frac{\partial^{2} U_{1}^{P}\left(z^{\prime}, s\right)}{\partial z^{\prime 2}}-s^{2} U_{1}^{P}\left(z^{\prime}, s\right)-\frac{2 \pi r_{11}}{\rho_{1}^{P} A_{1}^{P}}\left(G_{11}^{S}+c_{11}^{S} s\right) \sum_{n=1}^{\infty} q_{11 n}^{S}\left\{\left[-B_{11 n}^{S} I_{1}\left(q_{11 n}^{S} r_{11}\right)+C_{11 n}^{S} K_{1}\left(q_{11 n}^{S} r_{11}\right)\right] \cos \left(h_{11 n}^{S} z^{\prime}-\varphi_{11 n}^{S}\right)\right\}=0
$$

where $V_{1}^{P}=\sqrt{E_{1}^{P} / \rho_{1}^{P}}, U_{1}^{P}$ is the Laplace transform of $u_{1}^{P}$.

The general solution for Equation (18) is obtained by:

$$
U_{1}^{P^{\prime}}=D_{1}^{P} \cos \left(\frac{\omega}{V_{1}^{P}} z^{\prime}\right)+D_{1}^{P^{\prime}} \sin \left(\frac{\omega}{V_{1}^{P}} z^{\prime}\right)
$$

In addition, the corresponding particular solution can be given by

$$
U_{1}^{P *}=\sum_{n=1}^{\infty} M_{1 n}^{S} \cos \left(h_{11 n}^{S} z^{\prime}-\varphi_{11 n}^{S}\right)
$$

where $M_{1 n}^{S}=\frac{2 \pi r_{11} q_{11 n}^{S}}{\rho_{1}^{P} A_{1}^{P}} \frac{\left(G_{11}^{S}+i \omega \times c_{11}^{S}\right)}{\left(V_{1}^{P} h_{11 n}^{S}\right)^{2}-\omega^{2}}\left[B_{11 n}^{S} I_{1}\left(q_{11 n}^{S} r_{11}\right)-C_{11 n}^{S} K_{1}\left(q_{11 n}^{S} r_{11}\right)\right]$.

Therefore, the solution for Equation (18) can be obtained as

$$
U_{1}^{P}=\sum_{n=1}^{\infty} M_{1 n}^{S} \cos \left(h_{11 n}^{S} z^{\prime}-\varphi_{11 n}^{S}\right)+D_{1}^{P} \cos \left(\frac{\omega}{V_{1}^{P}} z^{\prime}\right)+D_{1}^{P^{\prime}} \sin \left(\frac{\omega}{V_{1}^{P}} z^{\prime}\right)
$$

Furthermore, according to the continuity conditions in Equation (10), the following expression can be given by

$$
\begin{aligned}
& \sum_{n=1}^{\infty}\left[B_{11 n}^{S} I_{0}\left(q_{11 n}^{S} r_{11}\right)+C_{11 n}^{S} K_{0}\left(q_{11 n}^{S} r_{11}\right)\right] \cos \left(h_{11 n}^{S} z^{\prime}-\varphi_{11 n}^{S}\right) \\
& =D_{1}^{P} \cos \left(\frac{\omega}{V_{1}^{P}} z^{\prime}\right)+D_{1}^{P^{\prime}} \sin \left(\frac{\omega}{V_{1}^{P}} z^{\prime}\right)+\sum_{n=1}^{\infty} M_{1 n}^{S} \cos \left(h_{11 n}^{S} z^{\prime}-\varphi_{11 n}^{S}\right)
\end{aligned}
$$

Combining Equations (16), (17), (21), and (22) yields

$$
U_{1}^{P}=D_{1}^{P}\left[\sum_{n=1}^{\infty} \gamma_{1 n}^{\prime} \cos \left(h_{11 n}^{S} z^{\prime}-\varphi_{11 n}^{S}\right)+\cos \left(\frac{\omega}{V_{1}^{P}} z^{\prime}\right)\right]+D_{1}^{P^{\prime}}\left[-\sum_{n=1}^{\infty} \gamma_{1 n}^{\prime \prime} \cos \left(h_{11 n}^{S} z^{\prime}-\varphi_{11 n}^{S}\right)+\sin \left(\frac{\omega}{V_{1}^{P}} z^{\prime}\right)\right]
$$


where $\gamma_{1 n}^{\prime}$ and $\gamma_{1 n}^{\prime \prime}$ are presented in Appendix B.

Performing the recursion of the transfer function method, $Z_{m}^{p}$ is obtained as

$$
Z_{m}^{p}(\omega)=\frac{F_{m}}{U_{m}^{p}}=-E_{m}^{P} A_{m}^{P} \frac{\frac{D_{m}^{P}}{D_{m}^{p \prime}} \sum_{n=1}^{\infty} \gamma_{m n}^{\prime} h_{m 1 n}^{S} \sin \left(\varphi_{m 1 n}^{S}\right)+\frac{\omega}{V_{m}^{p}}-\sum_{n=1}^{\infty} \gamma_{m n}^{\prime \prime} h_{m 1 n}^{S} \sin \left(\varphi_{m 1 n}^{S}\right)}{\frac{D_{m}^{p}}{D_{m}^{p \prime}}\left(1+\sum_{n=1}^{\infty} \gamma_{m n}^{\prime} \cos \left(\varphi_{m 1 n}^{S}\right)\right)-\sum_{n=1}^{\infty} \gamma_{m n}^{\prime \prime} \cos \left(\varphi_{m 1 n}^{S}\right)}=\frac{E_{m}^{P} A_{m}^{P}}{l_{m}} K_{d}^{\prime}
$$

where $K_{d}^{\prime}=\frac{\frac{D_{m}^{P}}{D_{m}^{P}} \sum_{n=1}^{\infty} \gamma_{m n}^{\prime} \bar{h}_{m 1 n}^{S} \sin \left(\varphi_{m 1 n}^{S}\right)+\theta_{m}-\sum_{n=1}^{\infty} \gamma_{m n}^{\prime \prime} \bar{h}_{m 1 n}^{S} \sin \left(\varphi_{m 1 n}^{S}\right)}{\frac{D_{m}^{P}}{D_{m}^{P}}\left(1+\sum_{n=1}^{\infty} \gamma_{m n}^{\prime} \cos \left(\varphi_{m 1 n}^{S}\right)\right)-\sum_{n=1}^{\infty} \gamma_{m n}^{\prime \prime} \cos \left(\varphi_{m 1 n}^{S}\right)}$ is the dimensionless complex impedance; $\frac{D_{m}^{P}}{D_{m}^{P}}=\frac{\theta_{m} \cos \left(\theta_{m}\right)+\sum_{n=1}^{\infty} \gamma_{m n}^{\prime \prime} \bar{h}_{m 1 n}^{S} \sin \left(\bar{h}_{m 1 n}^{S}-\varphi_{m 1 n}^{S}\right)+\frac{Z_{m-1}^{P} l_{m}}{E_{m}^{P} A_{m}^{P}}\left[\sin \left(\theta_{m}\right)-\sum_{n=1}^{\infty} \gamma_{m n}^{\prime \prime} \cos \left(\bar{h}_{m 1 n}^{S}-\varphi_{m 1 n}^{S}\right)\right]}{\theta_{m} \sin \left(\theta_{m}\right)+\sum_{n=1}^{\infty} \gamma_{m n}^{\prime} \bar{h}_{m 1 n}^{S} \sin \left(\bar{h}_{m 1 n}^{S}-\varphi_{m 1 n}^{S}\right)-\frac{Z_{m-1}^{P} l_{m}}{E_{m}^{P} A_{m}^{P}}\left[\cos \left(\theta_{m}\right)+\sum_{n=1}^{\infty} \gamma_{m n}^{\prime} \cos \left(\bar{h}_{m 1 n}^{S}-\varphi_{m 1 n}^{S}\right)\right]}, F_{m}$ denotes the Laplace transform of $p(t)$; The displacement impedance function of the first and $i$ th pile segments is given in Appendix C.

Further, the dimensionless complex impedance $K_{d}^{\prime}$ can be expressed as

$$
K_{d}^{\prime}=K_{r}+i K_{i}
$$

where $K_{r}$ denotes the true stiffness, and $K_{i}$ represents the equivalent damping.

With respect to the semi-sine wave $p(t)=Q_{\max } \times \sin (\pi t / T)$, the velocity response in the time domain is obtained by the inverse Fourier transform:

$$
V_{v}(t)=Q_{\max } I F T\left[-\frac{1}{\rho_{m}^{P} A_{m}^{P} V_{m}^{P}} H_{v}^{\prime} \frac{\pi T}{\pi^{2}-T^{2} \omega^{2}}\left(1+e^{-i \omega T}\right)\right]=-\frac{Q_{\max }}{\rho_{m}^{P} A_{m}^{P} V_{m}^{P}} V_{v}^{\prime}
$$

where $V_{v}^{\prime}=0.5 \times \int_{-\infty}^{\infty}\left[\frac{\left(1+e^{-i \theta \bar{T}} \bar{T}\right.}{\pi^{2}-\bar{T}^{2} \bar{\omega}^{2}} H_{v}^{\prime}\right] e^{i \theta t^{\prime}} d \bar{\omega} ; Q_{\max }$ denotes the amplitude of the exciting pressure; $T$ represents the impulse width of the exciting pressure; $\bar{T}=T / T_{\mathcal{C}}$ denotes the corresponding dimensionless impulse width; $V_{m}^{P}=\sqrt{E_{m}^{P} / \rho_{m}^{P}} ; T_{c}=\sum_{i=1}^{m} t_{i c} ; t^{\prime}=t / T_{c}$ represents dimensionless time; $\bar{\omega}=\omega T_{c}$; the dimensionless frequency response function $H_{v}^{\prime}(\omega)$ is given in Appendix D.

\section{Results and Discussion}

Numerical analyses are illustrated to verify the acquired solutions by comparison with prior solutions and to investigate the characteristics of a floating pile in bidirectional heterogeneous media with a viscous-type damping model. EI Naggar [29] and Wang et al. [30] pointed out that stable solutions can be obtained if $m^{\prime}>20$. Hence, the value of $m^{\prime}$ is taken as 20 in this paper. The coefficient of the disturbance degree $\xi_{i}^{S}$ is defined as:

$$
\xi_{i}^{S}=\sqrt{G_{i 1}^{S} / G_{i\left(m^{\prime}+1\right)}^{S}}=\sqrt{c_{i 1}^{S} / c_{i\left(m^{\prime}+1\right)}^{S}}=V_{i 1}^{S} / V_{i\left(m^{\prime}+1\right)}^{S}(i=1,2, \ldots, m)
$$

If $\xi_{i}{ }^{S}<1$, the soil layer is weakened; if $\xi_{i}{ }^{S}>1$, the soil layer is strengthened; if $\xi_{i}{ }^{S}=1$, the soil layer is radially homogeneous.

Unless otherwise specified, some parameters are employed in the following analyses:

$r_{i 1}=b_{i}=0.5 \mathrm{~m}, \rho_{i}^{p}=2500 \mathrm{~kg} / \mathrm{m}^{3}, V_{i}^{p}=3200 \mathrm{~m} / \mathrm{s}, H=20 \mathrm{~m}, k_{\mathrm{p}}=1 \times 10^{5} \mathrm{kN} / \mathrm{m}^{3}, \delta_{\mathrm{p}}=$ $1 \times 10^{5} \mathrm{kN} \cdot \mathrm{s} / \mathrm{m}^{2}, \rho_{i j}^{S}=2000 \mathrm{~kg} / \mathrm{m}^{3}, V_{i\left(m^{\prime}+1\right)}=100 \mathrm{~m} / \mathrm{s}, \mu_{i j}^{S}=0.4, c_{i\left(m^{\prime}+1\right)}=1 \mathrm{kN} \cdot \mathrm{s} / \mathrm{m}^{2}, \xi_{i}^{S}=0.6$, $m=5, m^{\prime}=20$. 


\subsection{Verification of the Solution}

The dimensionless complex impedance $K^{\prime}{ }_{\mathrm{d}}$ written in Equation (25) is degenerated to depict the longitudinal dynamic characteristics in homogeneous soil by setting $\xi_{i}^{S} \rightarrow 1(i=1,2, \ldots, m)$. Then, the present solution of $K^{\prime}{ }_{\mathrm{d}}$ is validated by comparing it with the solution of $\mathrm{Hu}$ et al. [15]. It is very clear from Figure 3 that with different values of pile length $H$, the present solution agrees well with that derived by $\mathrm{Hu}$ et al. [15]. Furthermore, Figure 4 show that the present solution also agrees well with the existing solution of Yang et al. [31] by setting $c_{i j}^{S} \rightarrow 0$. Hence, the validity of the present solution has been examined with the contrasts above.

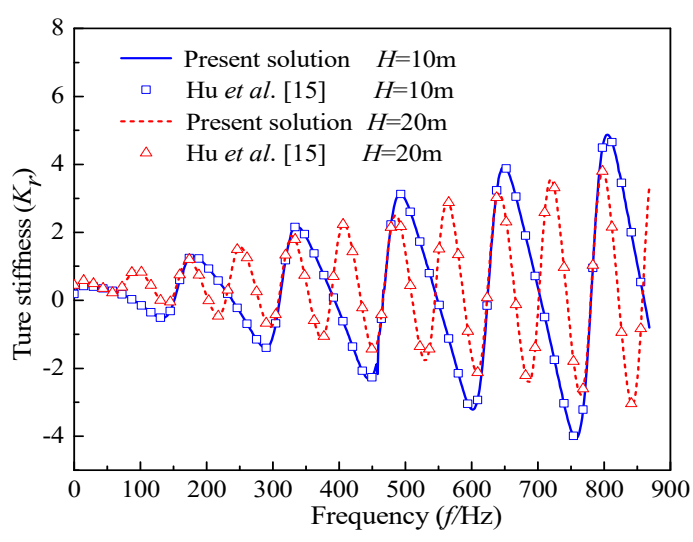

(a)

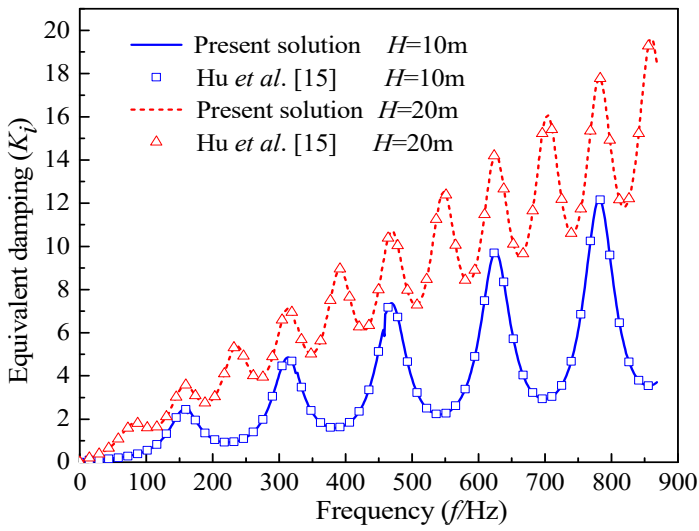

(b)

Figure 3. Contrast of the obtained solution $\left(\xi_{i}^{S} \rightarrow 1\right)$ with the solution of Hu et al. [15] $\left(r_{i 1}=0.5 \mathrm{~m}\right.$, $\left.m=0, m^{\prime}=0\right) ;(\mathbf{a})$ true stiffness; (b) equivalent damping.

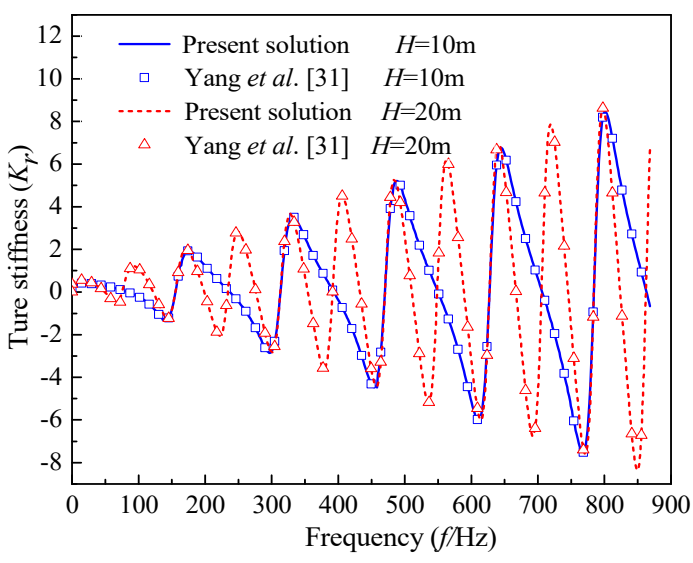

(a)

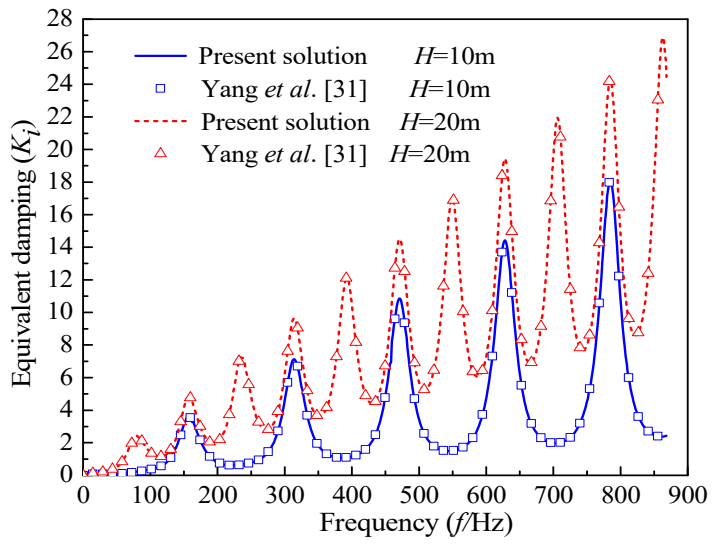

(b)

Figure 4. Contrast of the obtained solution $\left(c_{i j}^{S} \rightarrow 0\right)$ with the prior solution of Yang et al. [31] $\left(r_{i 1}=0.5 \mathrm{~m}, b_{i}=0.5 \mathrm{~m}, H=20 \mathrm{~m}, \xi_{i}=0.6, m=0, m^{\prime}=20\right) ;(\mathbf{a})$ true stiffness; (b) equivalent damping.

\subsection{Parametric Analyses}

Figures 5 and 6 show the influence of the soil weakening degree on the complex impedance and dynamic response, respectively. It is found that the weakening degree has a significant impact on both the complex impedance and dynamic response. The oscillation amplitudes of the complex impedance and dynamic response rise with an increasing weakening degree. Figures 7 and 8 show the effect of the soil strengthening degree on the complex impedance and dynamic response, respectively, of the pile shaft. It can be seen that both the complex impedance and dynamic response evidently depend on the strengthening degree. Specifically, the oscillation amplitudes of the complex impedance and 
dynamic response decrease with increasing strengthening degree. It is very clear that this phenomenon is consistent with the existing results of Yang et al. [31].

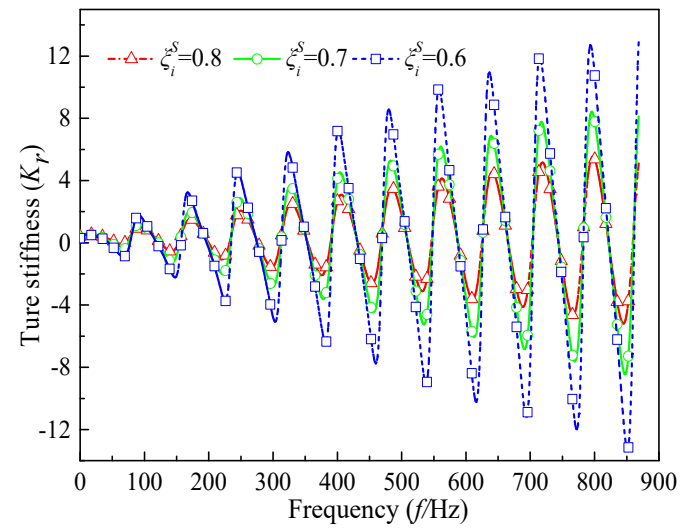

(a)

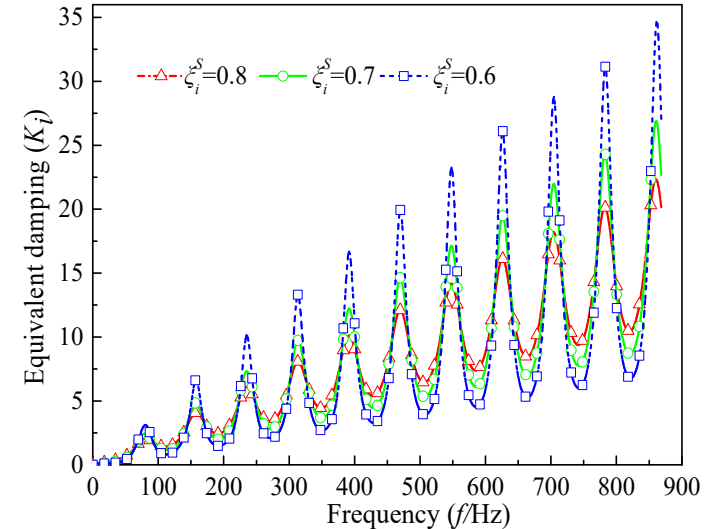

(b)

Figure 5. Influence of soil weakening degree on the complex impedance $\left(H=20 \mathrm{~m}, r_{i 1}=0.5 \mathrm{~m}\right.$, $\left.b_{i}=0.5 \mathrm{~m}, V_{i\left(m^{\prime}+1\right)}=100 \mathrm{~m} / \mathrm{s}, m=5, m^{\prime}=20\right)$; (a) true stiffness; (b) equivalent damping.

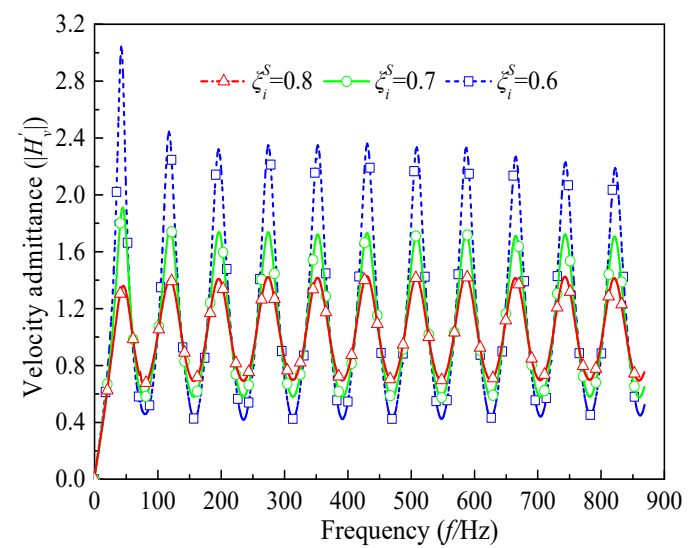

(a)

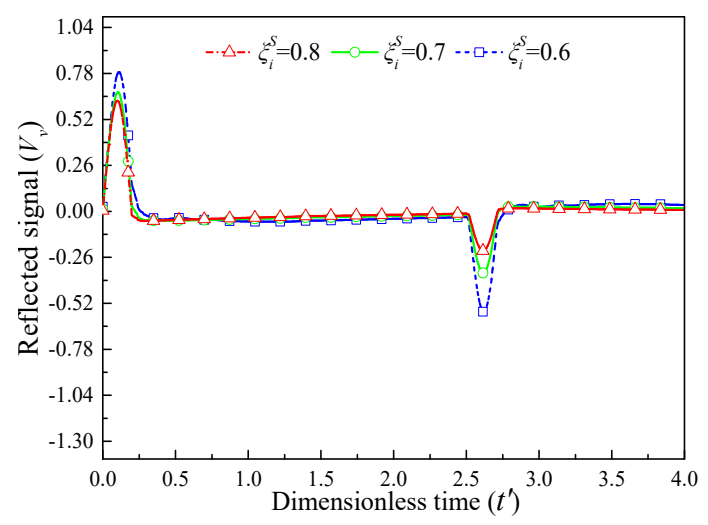

(b)

Figure 6. Influence of soil weakening degree on the dynamic response $\left(H=20 \mathrm{~m}, r_{i 1}=0.5 \mathrm{~m}, b_{i}=0.5 \mathrm{~m}\right.$, $\left.V_{i\left(m^{\prime}+1\right)}=100 \mathrm{~m} / \mathrm{s}, m=5, m^{\prime}=20\right) ;(\mathbf{a})$ velocity admittance; (b) reflected signal.

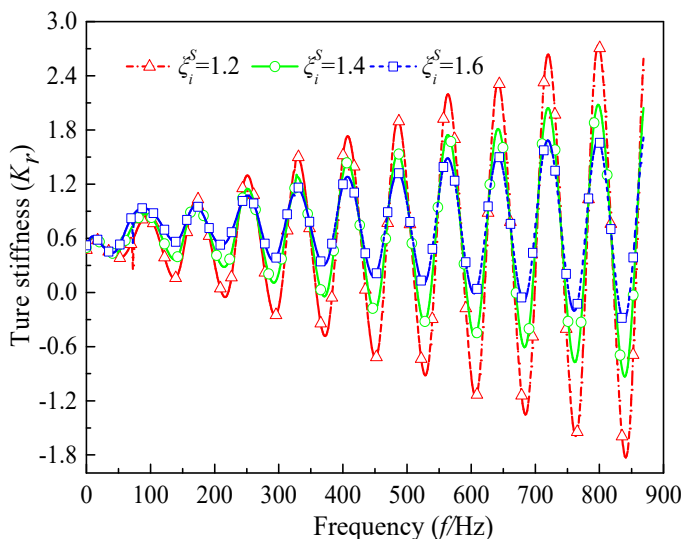

(a)

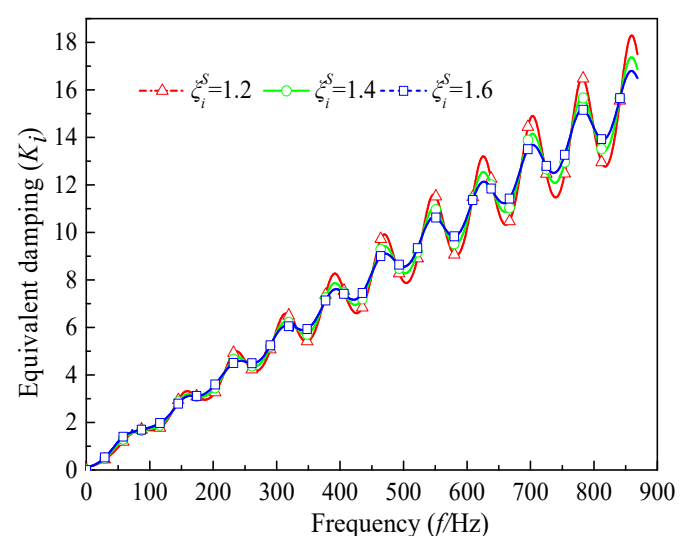

(b)

Figure 7. Influence of soil strengthening degree on the complex impedance $\left(H=20 \mathrm{~m}, r_{i 1}=0.5 \mathrm{~m}\right.$, $\left.b_{i}=0.5 \mathrm{~m}, V_{i\left(m^{\prime}+1\right)}=100 \mathrm{~m} / \mathrm{s}, m=5, m^{\prime}=20\right)$; (a) true stiffness; (b) equivalent damping. 


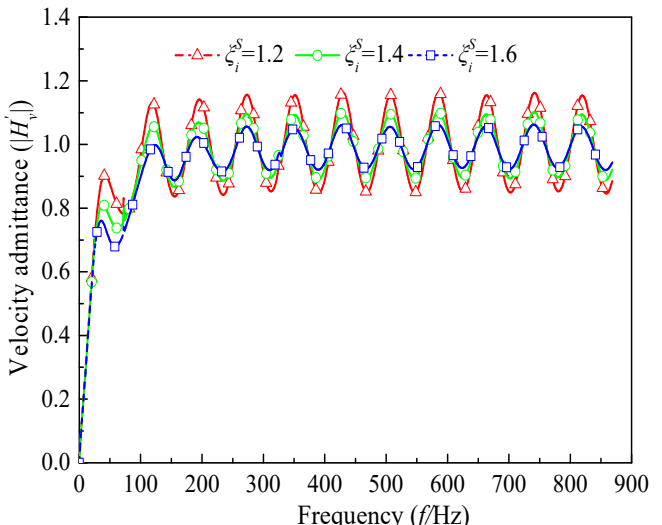

(a)

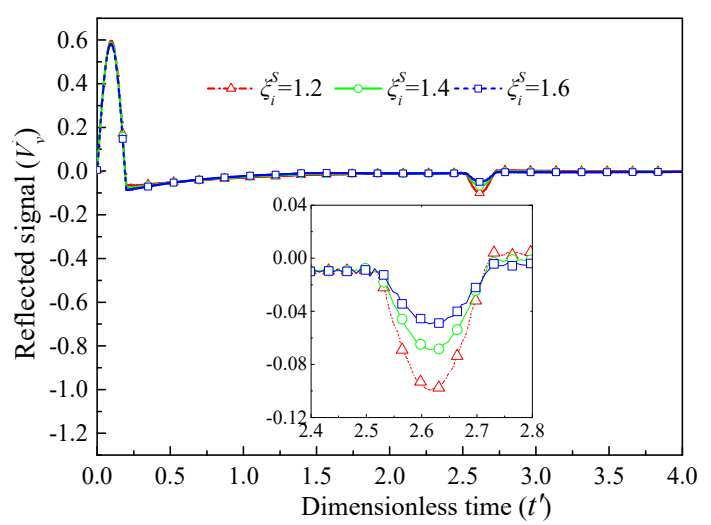

(b)

Figure 8. Effect of soil strengthening degree due to construction disturbance on the dynamic response $\left(H=20 \mathrm{~m}, r_{i 1}=0.5 \mathrm{~m}, b_{i}=0.5 \mathrm{~m}, V_{i\left(m^{\prime}+1\right)}=100 \mathrm{~m} / \mathrm{s}, m=5, m^{\prime}=20\right) ;($ a) velocity admittance; (b) reflected signal.

For a given coefficient of the disturbance degree, i.e., $\xi_{i}^{S}=0.6$, the effects of the weakened soil radius on complex impedance and the dynamic response are shown in Figures 9 and 10, respectively. It is very clear that the oscillation amplitudes of the complex impedance and dynamic response become greater with the increase of the softened radius of disturbed zone. Figures 11 and 12 depict the effect of the strengthened soil radius of the disturbed zone on the complex impedance and dynamic response, respectively, of the pile shaft. In contrast, the oscillation amplitudes of the complex impedance and dynamic response increase with the decrease of the strengthened radius. Moreover, the effect of the softened or strengthened radius on the resonance frequencies of complex impedance and velocity admittance is negligible. Furthermore, the change of the disturbance radius of soil induces no further additional effects on the complex impedance and dynamic response when the disturbance radius reaches a critical value, e.g., $b_{i}=0.5 r_{i 1}$.

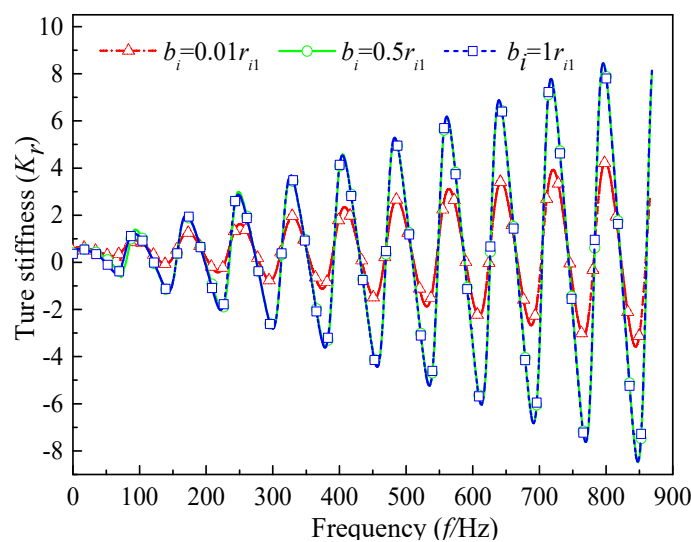

(a)

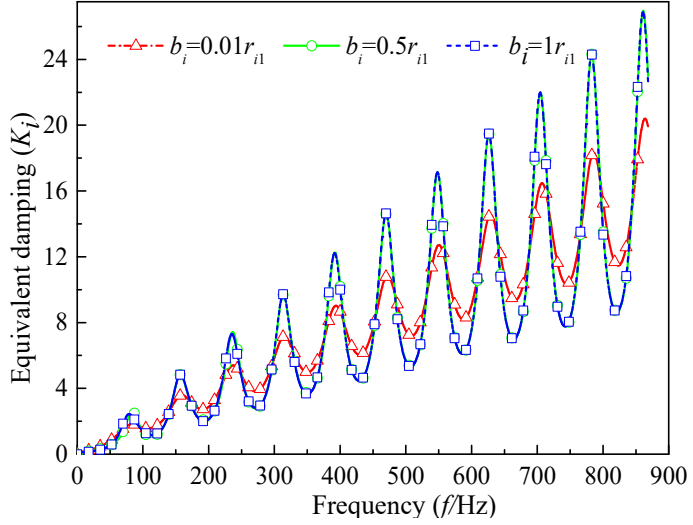

(b)

Figure 9. Influence of weakened soil radius on the complex impedance $\left(H=20 \mathrm{~m}, r_{i 1}=0.5 \mathrm{~m}\right.$, $\left.V_{i\left(m^{\prime}+1\right)}=100 \mathrm{~m} / \mathrm{s}, \xi_{i}=0.6, m=5, m^{\prime}=20\right)$; (a) true stiffness; (b) equivalent damping. 


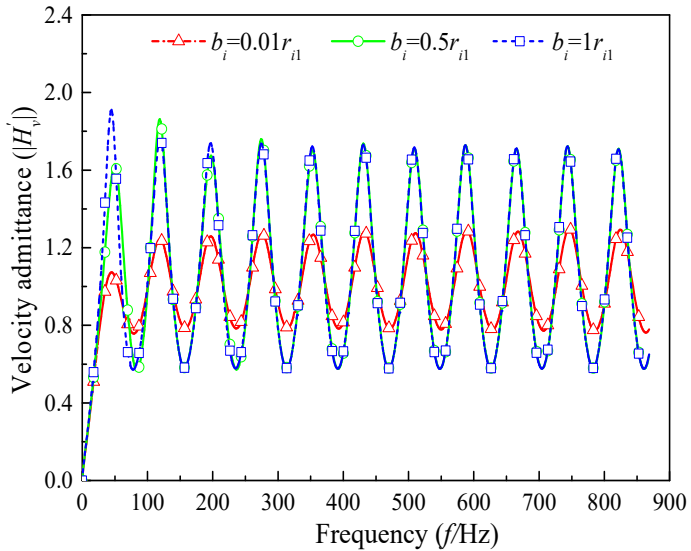

(a)

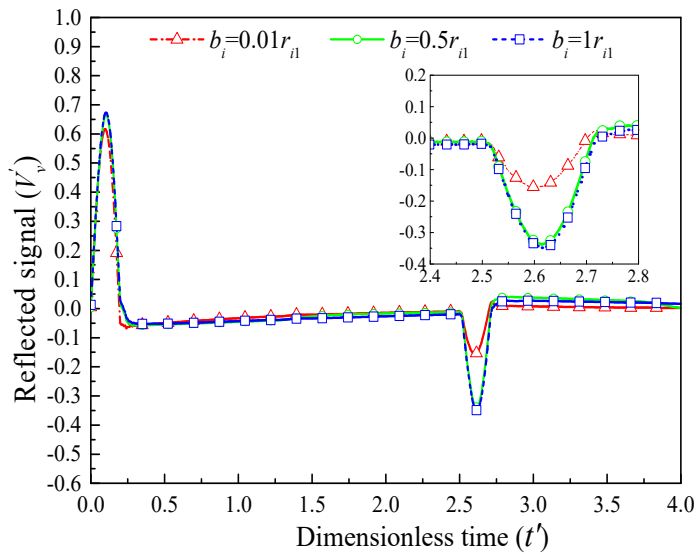

(b)

Figure 10. Influence of weakened soil radius on the dynamic response $\left(H=20 \mathrm{~m}, r_{i 1}=0.5 \mathrm{~m}\right.$, $\left.V_{i\left(m^{\prime}+1\right)}=100 \mathrm{~m} / \mathrm{s}, \xi_{i}=0.6, m=5, m^{\prime}=20\right)$; (a) velocity admittance; (b) reflected signal.

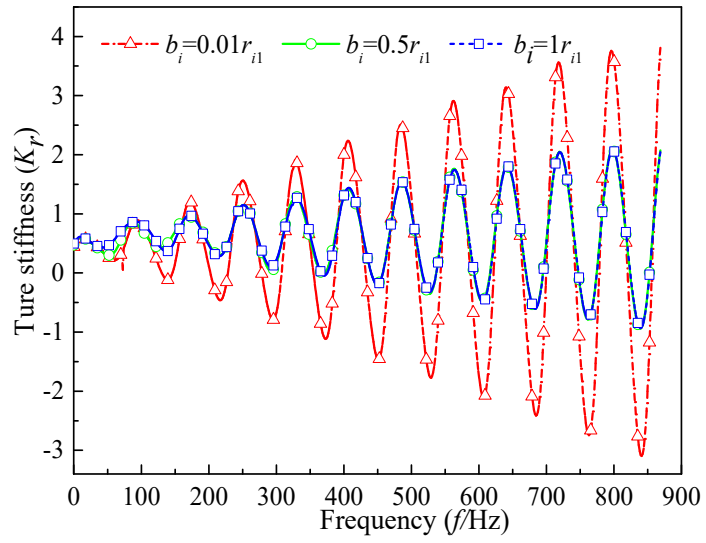

(a)

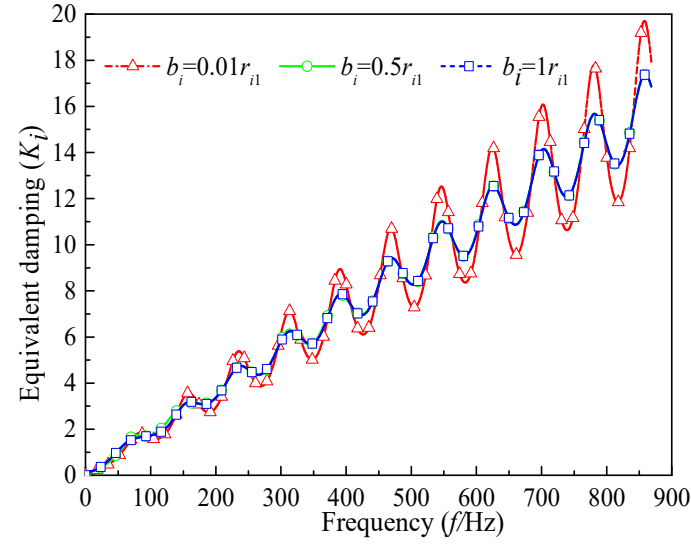

(b)

Figure 11. Influence of strengthened soil radius on the complex impedance $\left(H=20 \mathrm{~m}, r_{i 1}=0.5 \mathrm{~m}\right.$, $\left.V_{i\left(m^{\prime}+1\right)}=100 \mathrm{~m} / \mathrm{s}, \xi_{i}=1.4, m=5, m^{\prime}=20\right)$; (a) true stiffness; (b) equivalent damping.

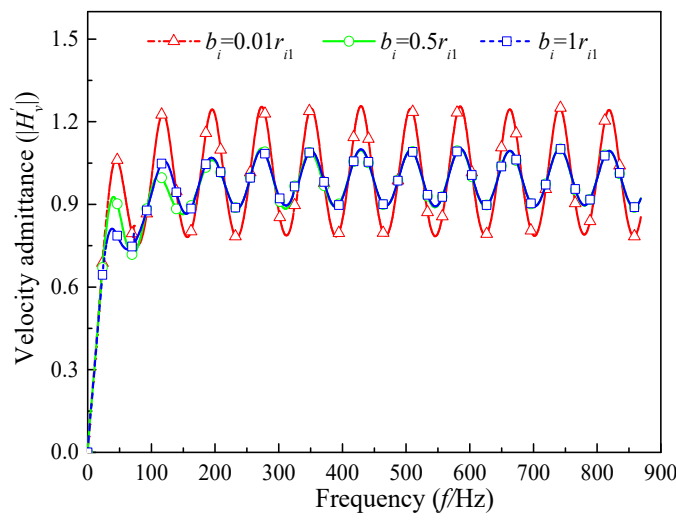

(a)

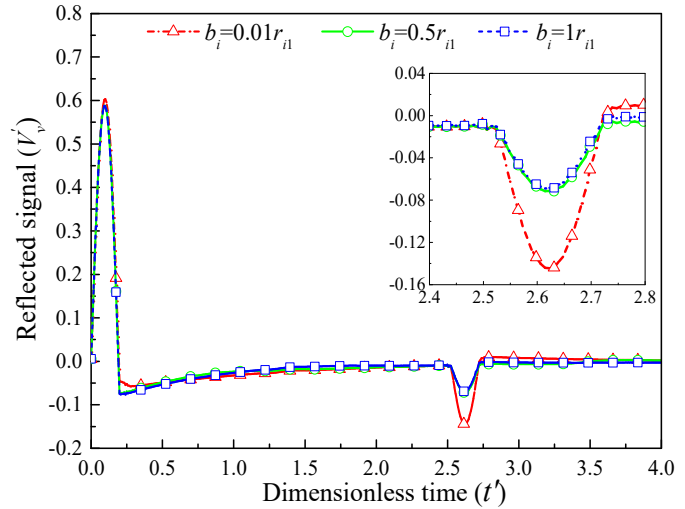

(b)

Figure 12. Influence of strengthened soil radius on the dynamic response $\left(H=20 \mathrm{~m}, r_{i 1}=0.5 \mathrm{~m}\right.$, $\left.V_{i\left(m^{\prime}+1\right)}=100 \mathrm{~m} / \mathrm{s}, \xi_{i}=1.4, m=5, m^{\prime}=20\right)$; (a) velocity admittance; (b) reflected signal. 


\section{Conclusions}

Based on the theory of wave propagation in a 3D continuum, a new approach for the longitudinal vibration of a floating pile is proposed by extending the complex stiffness method with the viscous-type damping model. The analytical solutions for the longitudinal impedance and dynamic response are achieved and validated by comparison with prior solutions.

The results of parametric analyses show that: (i) the oscillation amplitudes of the complex impedance and dynamic response of the pile shaft decline with the increase in the soil disturbance degree; (ii) the oscillation amplitudes of the complex impedance and dynamic response for the pile shaft depend significantly on the disturbance radius of the surrounding soil, while the effect on the resonance frequencies of the complex impedance and velocity admittance is nearly negligible; (iii) It is essential to take the influence of the construction effects on the pile into consideration to improve the rationality and reliability of pile design.

The presented approach and corresponding solutions can provide a more wide-ranging application for longitudinal vibration analysis of a floating pile in layered soils with radial inhomogeneity, which can be easily degenerated to examine the integrity detection for the longitudinal vibration of a floating pile or an end-bearing pile in layered soils with radial homogeneity. The heterogeneous effect model can also be extended to some important research fields (such as biophysics and physical chemistry, etc.) where diffusion may become abnormal due to crowded heterogeneity.

Author Contributions: Conceptualization, Methodology, Software, Writing-Original draft preparation, Z.L.; Project administration, Funding acquisition, Writing-Reviewing and Editing, Supervision, Resources, Formal analysis, C.C.; Investigation, Data curation, K.M.; Software, Validation, Y.X.; Software, Validation, H.P.; Supervision, Visualization, H.L. All authors have read and agreed to the published version of the manuscript.

Funding: This work is supported by the National Natural Science Foundation of China (Grant No. 51878109, 51778107 and 51578100), the Fundamental Research Funds for the Central Universities (Grant No. 3132019601), China Scholarship Council (CSC No. 201806570004), and the Cultivation project of Innovation talent for a doctorate student (BSCXXM022).

Acknowledgments: The corresponding author would like to acknowledge the support from the State Key Laboratory of Coastal and Offshore Engineering, Dalian University of Technology.

Conflicts of Interest: The authors declare no conflict of interest.

\section{Appendix A}

Setting $z^{\prime}=z-h_{i}$, the following expression can be obtained according to the variable separation method:

$$
U_{i j}^{S}(r, z, s)=R_{i j}^{S}(r) Z_{i j}^{S}\left(z^{\prime}\right)
$$

Inserting Equation (A1) into Equation (14) with rearrangement produces

$$
\left(\lambda_{i j}^{S}+2 G_{i j}^{S}+\delta_{i j}^{S} s\right) \frac{1}{Z_{i j}^{S}} \frac{\partial^{2} Z_{i j}^{S}}{\partial z^{\prime 2}}-\rho_{i j}^{S} s^{2}+\left(G_{i j}^{S}+c_{i j}^{S} s\right) \frac{1}{R_{i j}^{S}}\left(\frac{1}{r} \frac{\partial R_{i j}^{S}}{\partial r}+\frac{\partial^{2} R_{i j}^{S}}{\partial r^{2}}\right)=0
$$

Then, Equation (A2) can be further separated into

$$
\begin{gathered}
\frac{\partial^{2} Z_{i j}^{S}}{\partial z^{\prime 2}}+\left(h_{i j}^{S}\right)^{2} Z_{i j}^{S}=0 \\
\frac{d^{2} R_{i j}^{S}}{d r^{2}}+\frac{1}{r} \frac{d R_{i j}^{S}}{d r}-\left(q_{i j}^{S}\right)^{2} R_{i j}^{S}=0
\end{gathered}
$$

where $q_{i j}^{S}$ and $h_{i j}^{S}$ are undetermined coefficients which satisfy the following expression.

$$
-\left(\lambda_{i j}^{S}+2 G_{i j}^{S}+c_{i j}^{S} s\right)\left(h_{i j}^{S}\right)^{2}+\left(G_{i j}^{S}+c_{i j}^{S} s\right)\left(q_{i j}^{S}\right)^{2}=\rho_{i j}^{S} s^{2}
$$


Further, Equation (A6) is expressed as

$$
\left(q_{i j}^{S}\right)^{2}=\frac{\left(\lambda_{i j}^{S}+2 G_{i j}^{S}+c_{i j}^{S} s\right)\left(h_{i j}^{S}\right)^{2}+\rho_{i j}^{S} s^{2}}{\left(G_{i j}^{S}+c_{i j}^{S} s\right)}
$$

Hence, the general solution of Equations (A3) and (A4) can be obtained as

$$
\begin{gathered}
Z_{i j}^{S}\left(z^{\prime}\right)=C_{i j}^{S} \cos \left(h_{i j}^{S} z^{\prime}\right)+D_{i j}^{S} \sin \left(h_{i j}^{S} z^{\prime}\right) \\
R_{i j}^{S}\left(z^{\prime}\right)=A_{i j}^{S} I_{0}\left(q_{i j}^{S} r\right)+B_{i j}^{S} K_{0}\left(q_{i j}^{S} r\right)
\end{gathered}
$$

where $A_{i j}^{S}, B_{i j}^{S}, C_{i j}^{S}$, and $D_{i j}^{S}$ are undetermined coefficients; $I_{0}\left(q_{i j}^{S} r\right)$ and $K_{0}\left(q_{i j}^{S} r\right)$ present the $n$ th-type modified Bessel functions of order zero.

Substituting Equation (A1) into Equations (6) and (7) and performing the Laplace transform yields

$$
\begin{aligned}
& \left.\frac{d Z_{1 j}^{S}}{d z^{\prime}}\right|_{z^{\prime}=0}=\frac{k_{2 j}^{S}+s \delta_{2 j}^{S}}{E_{1 j}^{S}} Z_{1 j}^{S} \\
& \left.\frac{d Z_{1 j}^{S}}{d z^{\prime}}\right|_{z^{\prime}=l_{i}}=\frac{k_{1 j}^{S}+s \delta_{1 j}^{S}}{E_{1 j}^{S}} Z_{1 j}^{S}
\end{aligned}
$$

Thus, substituting Equation (A7) into Equations (A9) and (A10) gives

$$
\tan \left(h_{1 j}^{S} l_{1}\right)=\frac{\left(\bar{K}_{1 j}^{S}+\bar{K}_{1 j}^{S}{ }^{\prime}\right) h_{1 j}^{S} l_{1}}{\left(h_{1 j}^{S} l_{1}\right)^{2}-\bar{K}_{1 j}^{S} \bar{K}_{1 j^{\prime}}^{S}}
$$

where $\bar{K}_{1 j}^{S}=K_{1 j}^{S} l_{1} / E_{1 j^{\prime}}^{S} \bar{K}_{1 j}^{S^{\prime}}=K_{2 j}^{S} l_{1} / E_{1 j^{\prime}}^{S}, K_{1 j}^{S}=k_{1 j}^{S}+s \delta_{1 j^{\prime}}^{S} K_{2 j}^{S}=k_{2 j}^{S}+s \delta_{2 j}^{S}$.

When $r \rightarrow \infty$, The displacement of the outer zone is given by

$$
\left.U_{1 j}^{S}\right|_{r \rightarrow \infty}=0
$$

By combining Equations (A9)-(A12), we have

$$
U_{1 j}^{S}=\left\{\begin{array}{l}
\sum_{n=1}^{\infty} A_{1 j n}^{S} K_{0}\left(q_{1 j n}^{S} r\right) \cos \left(h_{1 j n}^{S} z^{\prime}-\varphi_{1 j n}^{S}\right) \quad\left(j=m^{\prime}+1\right) \\
\sum_{n=1}^{\infty}\left[B_{1 j n}^{S} I_{0}\left(q_{1 j n}^{S} r\right)+C_{1 j n}^{S} K_{0}\left(q_{1 j n}^{S} r\right)\right] \cos \left(h_{1 j n}^{S} z^{\prime}-\varphi_{1 j n}^{S}\right) \quad\left(j=m^{\prime}, \ldots, 2,1\right)
\end{array}\right.
$$

where $\varphi_{1 j n}^{S} z^{\prime}=\arctan \left(\bar{K}_{1 j n}^{S} / h_{1 j n}^{S} l_{1}\right), A_{1 j n^{\prime}}^{S} B_{1 j n^{\prime}}^{S} C_{1 j n}^{S}$ are undetermined coefficients.

\section{Appendix B}

$\gamma_{1 n}^{\prime}$ and $\gamma_{1 n}^{\prime \prime}$ can be expressed by

$$
\begin{aligned}
& \gamma_{1 n}^{\prime}=\gamma_{1 n}\left[\frac{\sin \left[\left(\frac{\omega}{V_{1}^{P}}-h_{11 n}^{S}\right) l_{1}+\varphi_{11 n}^{S}\right]-\sin \left(\varphi_{11 n}^{S}\right)}{\frac{\omega}{V_{1}^{P}}-h_{11 n}^{S}}+\frac{\sin \left[\left(\frac{\omega}{V_{1}^{P}}+h_{11 n}^{S}\right) l_{1}-\varphi_{11 n}^{S}\right]+\sin \left(\varphi_{11 n}^{S}\right)}{\frac{\omega}{V_{1}^{P}}+h_{11 n}^{S}}\right] \\
& \gamma_{1 n}^{\prime \prime}=\gamma_{1 n}\left[\frac{\cos \left[\left(\frac{\omega}{V_{1}^{P}}+h_{11 n}^{S}\right) l_{1}-\varphi_{11 n}^{S}\right]-\cos \left(\varphi_{11 n}^{S}\right)}{\frac{\omega}{V_{1}^{P}}+h_{11 n}^{S}}+\frac{\cos \left[\left(\frac{\omega}{V_{1}^{P}}-h_{11 n}^{S}\right) l_{1}+\varphi_{11 n}^{S}\right]-\cos \left(\varphi_{11 n}^{S}\right)}{\frac{\omega}{V_{1}^{P}}-h_{11 n}^{S}}\right]
\end{aligned}
$$


where $\gamma_{1 n}$ can be written as

$$
\gamma_{1 n}=-\frac{\left(1+i G_{1 c}^{\prime} \theta_{1}\right) \bar{q}_{11 n}^{S} \bar{\rho}_{11} \bar{v}_{11}^{2}}{\bar{r}_{11}\left(\left(\bar{h}_{11 n}^{S}\right)^{2}-\theta_{1}^{2}\right) \phi_{1 n}^{S} L_{1 n}^{S}}\left[K_{1}\left(\bar{q}_{11 n}^{S} \bar{r}_{11}\right)-P_{11 n}^{S} I_{1}\left(\bar{q}_{11 n}^{S} \bar{r}_{11}\right)\right]
$$

where $G_{1 c}^{\prime}=c_{11}^{S} /\left(G_{11}^{S} t_{1 c}\right), \bar{h}_{11 n}^{S}=l_{1} h_{11 n^{\prime}}^{S} \bar{q}_{1 n}^{\mathrm{s}}=l_{1} q_{1 n^{\prime}}^{\mathrm{s}}, \theta_{1}=\omega t_{1 c}, t_{1 c}=l_{1} / V_{1}^{p}, \bar{r}_{11}=r_{11} / l_{1}, \bar{v}_{11}=V_{11}^{S} / V_{1}^{P}$, $\bar{\rho}_{11}=\rho_{11}^{S} / \rho_{1}^{P}, \phi_{1 n}^{S}$ and $L_{1 n}^{S}$ can be written as

$$
\begin{gathered}
\phi_{1 n}^{S}=-P_{11 n}^{S}\left[I_{0}\left(q_{11 n}^{S} r_{11}\right)-\frac{2 \pi r_{11} q_{11 n}^{S}}{\rho_{1}^{P} A_{1}^{1 n}} \frac{\left(G_{11}^{S}+i \omega c_{11}^{S}\right)}{\left(V_{1}^{1} h_{11 n}^{S}\right)^{2}-\omega^{2}} I_{1}\left(q_{11 n}^{S} r_{11}\right)\right]+\left[K_{0}\left(q_{11 n}^{S} r_{11}\right)+\frac{2 \pi r_{11} q_{1 n}^{S}}{\rho_{1}^{11} A_{1}^{1}} \frac{\left(G_{11}^{S}+i \omega c_{11}^{S}\right)}{\left(V_{11}^{P} h_{11}^{S}\right)^{2}-\omega^{2}} K_{1}\left(q_{11 n}^{S} r_{11}\right)\right] \\
L_{1 n}^{S}=\int_{0}^{l_{1}} \cos ^{2}\left(h_{11 n}^{S} z^{\prime}-\varphi_{11 n}^{S}\right) d z^{\prime}
\end{gathered}
$$

\section{Appendix C}

Applying the Laplace transform to Equations (12) and (13) yields

$$
\begin{aligned}
& \left.\frac{d U_{1}^{P}}{d z^{\prime}}\right|_{z^{\prime}=0}=-\frac{Z_{1}^{P} U_{1}^{P}}{E_{1}^{P} A_{1}^{P}} \\
& \left.\frac{d U_{1}^{P}}{d z^{\prime}}\right|_{z^{\prime}=l_{1}}=-\frac{Z_{0}^{P} U_{1}^{P}}{E_{1}^{P} A_{1}^{P}}
\end{aligned}
$$

where $Z_{0}^{P}$ and $Z_{1}^{P}$ are the Laplace transform of $z_{0}^{P}$ and $z_{1}^{P}$, respectively; $z_{0}^{P}=k^{P}+i \omega \delta^{P}$.

Thus, the displacement impedance function of the first pile segment is given by:

$$
Z_{1}^{p}(\omega)=\frac{F_{1}}{U_{1}^{p}}=-E_{1}^{P} A_{1}^{P} \frac{\frac{D_{1}^{P}}{D_{1}^{P^{\prime}}} \sum_{n=1}^{\infty} h_{11 n}^{S} \gamma_{1 n}^{\prime} \sin \left(\varphi_{11 n}^{S}\right)+\frac{\omega}{V_{1}^{p}}-\sum_{n=1}^{\infty} \gamma_{1 n}^{\prime \prime} h_{11 n}^{S} \sin \left(\varphi_{11 n}^{S}\right)}{\left.\frac{D_{1}^{P}}{D_{1}^{P^{\prime}}}+\frac{D_{1}^{P}}{D_{1}^{P^{\prime}}} \sum_{n=1}^{\infty} \gamma_{1 n}^{\prime} h_{11 n}^{S} \cos \left(\varphi_{11 n}^{S}\right)\right)-\sum_{n=1}^{\infty} \gamma_{1 n}^{\prime \prime} \cos \left(\varphi_{11 n}^{S}\right)}
$$

where $F_{1}$ denotes the axial pressure on the head of the first pile segment; $\frac{D_{1}^{p}}{D_{1}^{p \prime}}=$ $\frac{\theta_{1} \cos \left(\theta_{1}\right)+\sum_{n=1}^{\infty} \gamma_{1 n}^{\prime \prime} \bar{h}_{11 n}^{S} \sin \left(\bar{h}_{11 n}^{S}-\varphi_{11 n}^{S}\right)+\frac{z_{0}^{P} l_{1}}{E_{1}^{P} A_{1}^{P}}\left[\sin \left(\theta_{1}\right)-\sum_{n=1}^{\infty} \gamma_{1 n}^{\prime \prime} \cos \left(\bar{h}_{11 n}^{S}-\varphi_{11 n}^{S}\right)\right]}{\theta_{1} \sin \left(\theta_{1}\right)+\sum_{n=1}^{\infty} \gamma_{1 n}^{\prime} \bar{h}_{11 n}^{S} \sin \left(\bar{h}_{11 n}^{S}-\varphi_{11 n}^{S}\right)-\frac{z_{0}^{P} l_{1}}{E_{1}^{P} A_{1}^{P}}\left[\cos \left(\theta_{1}\right)+\sum_{n=1}^{\infty} \gamma_{1 n}^{\prime} \cos \left(\bar{h}_{11 n}^{S}-\varphi_{11 n}^{S}\right)\right]}$.

Similarly, the displacement impedance function of the $i$ th pile segment at the upper interface is

$$
Z_{i}^{p}(\omega)=\frac{F_{i}}{U_{i}^{p}}=-E_{i}^{P} A_{i}^{P} \frac{\frac{D_{i}^{P}}{D_{i}^{P^{\prime}}} \sum_{n=1}^{\infty} \gamma_{i n}^{\prime} h_{i 1 n}^{S} \sin \left(\varphi_{i 1 n}^{S}\right)+\frac{\omega}{V_{i}^{p}}+-\sum_{n=1}^{\infty} \gamma_{i n}^{\prime \prime} h_{i 1 n}^{S} \sin \left(\varphi_{i 1 n}^{S}\right)}{\left.-\sum_{n=1}^{\infty} \gamma_{i n}^{\prime \prime} \cos \left(\varphi_{i 1 n}^{S}\right)+\frac{D_{i}^{P}}{D_{i}^{P^{\prime}}}+\frac{D_{i}^{P}}{D_{i}^{P^{\prime}}} \sum_{n=1}^{\infty} \gamma_{i n}^{\prime} \cos \left(\varphi_{i 1 n}^{S}\right)\right)}
$$

where $\frac{D_{i}^{P}}{D_{i}^{P^{\prime}}}, \gamma_{\text {in }}^{\prime}$ and $\gamma_{1 n}^{\prime \prime}$ are given by

$$
\frac{D_{i}^{P}}{D_{i}^{P \prime}}=\frac{\theta_{i} \cos \left(\theta_{i}\right)+\sum_{n=1}^{\infty} \gamma_{i n}^{\prime \prime} \bar{h}_{i 1 n}^{S} \sin \left(\bar{h}_{i 1 n}^{S}-\varphi_{i 1 n}^{S}\right)+\frac{Z_{i-1}^{P} l_{i}}{E_{i}^{P} A_{i}^{P}}\left[\sin \left(\theta_{i}\right)-\sum_{n=1}^{\infty} \gamma_{i n}^{\prime \prime} \cos \left(\bar{h}_{i 1 n}^{S}-\varphi_{i 1 n}^{S}\right)\right]}{-\frac{Z_{i-1}^{P} l_{i}}{E_{i}^{P} A_{i}^{P}}\left[\cos \left(\theta_{i}\right)+\sum_{n=1}^{\infty} \gamma_{i n}^{\prime} \cos \left(\bar{h}_{i 1 n}^{S}-\varphi_{i 1 n}^{S}\right)\right]+\theta_{i} \sin \left(\theta_{i}\right)+\sum_{n=1}^{\infty} \gamma_{i n}^{\prime} \bar{h}_{i 1 n}^{S} \sin \left(\bar{h}_{i 1 n}^{S}-\varphi_{i 1 n}^{S}\right)}
$$




$$
\begin{aligned}
& \gamma_{i n}^{\prime}=\gamma_{i n}\left[\frac{\sin \left[\left(\frac{\omega}{V_{i}^{p}}-h_{i 1 n}^{S}\right) l_{i}+\varphi_{i 1 n}^{S}\right]-\sin \left(\varphi_{i 1 n}^{S}\right)}{\frac{\omega}{V_{i}^{P}}-h_{i 1 n}^{S}}+\frac{\sin \left[\left(\frac{\omega}{V_{i}^{p}}+h_{i 1 n}^{S}\right) l_{i}-\varphi_{i 1 n}^{S}\right]+\sin \left(\varphi_{i 1 n}^{S}\right)}{\frac{\omega}{V_{i}^{p}}+h_{i 1 n}^{S}}\right] \\
& \gamma_{i n}^{\prime \prime}=\gamma_{i n}\left[\frac{\cos \left[\left(\frac{\omega}{V_{i}^{p}}+h_{i 1 n}^{S}\right) l_{i}-\varphi_{i 1 n}^{S}\right]-\cos \left(\varphi_{i 1 n}^{S}\right)}{\frac{\omega}{V_{i}^{p}}+h_{i 1 n}^{S}}+\frac{\cos \left[\left(\frac{\omega}{V_{i}^{p}}-h_{i 1 n}^{S}\right) l_{i}+\varphi_{i 1 n}^{S}\right]-\cos \left(\varphi_{i 1 n}^{S}\right)}{\frac{\omega}{V_{i}^{p}}-h_{i 1 n}^{S}}\right]
\end{aligned}
$$

where $\gamma_{\text {in }}$ can be written as

$$
\gamma_{i n}=-\frac{\left(1+i G_{i c}^{\prime} \theta_{i}\right) \bar{q}_{i 1 n}^{S} \bar{\rho}_{i 1} \bar{v}_{i 1}^{2}}{\bar{r}_{i 1}\left(\left(\bar{h}_{i 1 n}^{S}\right)^{2}-\theta_{i}^{2}\right) \varphi_{i n}^{S} L_{i n}^{S}}\left[K_{1}\left(\bar{q}_{i 1 n}^{S} \bar{r}_{i 1}\right)-P_{i 1 n}^{S} I_{1}\left(\bar{q}_{i 1 n}^{S} \bar{r}_{i 1}\right)\right]
$$

where $\varphi_{i 1 n}^{S}=\arctan \left(\bar{K}_{i 1}^{S^{\prime}} / h_{i 1 n}^{S} l_{i}\right), G_{i c}^{\prime}=c_{i 1}^{S} /\left(G_{i 1}^{S} t_{i c}\right), \bar{h}_{i 1 n}^{S}=l_{i} h_{i 1 n^{\prime}}^{S} \bar{q}_{1 n}^{\mathrm{s}}=l_{1} q_{1 n^{\prime}}^{\mathrm{S}}, \theta_{i}=\omega t_{i c}, t_{i c}=l_{i} / V_{i}^{p}$, $\bar{r}_{i 1}=r_{i 1} / l_{i}, \bar{v}_{i 1}=V_{i 1}^{S} / V_{i}^{P}, \bar{\rho}_{i 1}=\rho_{i 1}^{S} / \rho_{i}^{P}$, $\phi_{i n}^{S}$ and $L_{i n}^{S}$ can be written as

$$
\begin{gathered}
\phi_{i n}^{S}=P_{i 1 n}^{S}\left[I_{0}\left(q_{i 1 n}^{S} r_{i 1}\right)-\frac{2 \pi r_{i 1} q_{i n n}^{S}}{\rho_{i}^{P} A_{i}^{P}} \frac{\left(G_{i 1}^{S}+i \omega c_{i 1}^{S}\right)}{\left(V_{i}^{P} h_{i 1 n}^{S}\right)^{2}-\omega^{2}} I_{1}\left(q_{i 1 n}^{S} r_{i 1}\right)\right]-\left[K_{0}\left(q_{i 1 n}^{S} r_{i 1}\right)+\frac{2 \pi r_{i 1} q_{i 1 n}^{S}}{\rho_{i}^{P} A_{i}^{P}} \frac{\left(G_{i 1}^{S}+i \omega c_{i 1}^{S}\right)}{\left(V_{i}^{P} h_{i 1 n}^{S}\right)^{2}-\omega^{2}} K_{1}\left(q_{i 1 n}^{S} r_{i 1}\right)\right] \\
L_{i n}^{S}=\int_{0}^{l_{i}} \cos ^{2}\left(h_{i 1 n}^{S} z^{\prime}-\varphi_{i 1 n}^{S}\right) d z^{\prime}
\end{gathered}
$$

\section{Appendix D}

Based on Equation (24), the frequency response function is easily achieved by

$$
H_{u}(\omega)=\frac{U_{m}^{p}}{F_{m}}=\frac{1}{Z_{m}^{p}(\omega)}=-\frac{l_{m}}{E_{m}^{P} A_{m}^{P}} \frac{-\sum_{n=1}^{\infty} \gamma_{m n}^{\prime \prime} \cos \left(\varphi_{m 1 n}^{S}\right)+\frac{D_{m}^{p}}{D_{m}^{p}}\left(1+\sum_{n=1}^{\infty} \gamma_{m n}^{\prime} \cos \left(\varphi_{m 1 n}^{S}\right)\right)}{D_{m}^{p^{\prime}} \sum_{n=1}^{\infty} \gamma_{m n}^{\prime} \bar{h}_{m 1 n}^{S} \sin \left(\varphi_{m 1 n}^{S}\right)+\theta_{m}-\sum_{n=1}^{\infty} \gamma_{m n}^{\prime \prime} h_{m 1 n}^{S} \sin \left(\varphi_{m 1 n}^{S}\right)}=\frac{l_{m}}{E_{m}^{P} A_{m}^{P}} H_{u}^{\prime}(\omega)
$$

where $H_{u}^{\prime}(\omega)=\frac{\left.-\sum_{n=1}^{\infty} \gamma_{m n}^{\prime \prime} \cos \left(\varphi_{m 1 n}^{S}\right)+\frac{D_{m}^{P}}{D_{m}^{P^{\prime}}}+\frac{D_{m}^{P}}{D_{m}^{P^{\prime}}} \sum_{n=1}^{\infty} \gamma_{m n}^{\prime} \cos \left(\varphi_{m 1 n}^{S}\right)\right)}{\frac{D_{m}^{P}}{D_{m}^{P^{\prime}}} \sum_{n=1}^{\infty} \gamma_{m n}^{\prime} \bar{h}_{m 1 n}^{S} \sin \left(\varphi_{m 1 n}^{S}\right)-\sum_{n=1}^{\infty} \gamma_{m n}^{\prime \prime} h_{m 1 n}^{S} \sin \left(\varphi_{m 1 n}^{S}\right)+\theta_{m}}$ is the dimensionless frequency response function of displacement corresponding to $H_{u}(\omega)$.

In addition, the function of velocity admittance $H_{v}(\omega)$ can be obtained as

$$
H_{v}(\omega)=i \omega H_{u}(\omega)=-\frac{i \theta_{m}}{\rho_{m}^{P} A_{m}^{P} V_{m}^{P}} \frac{\frac{D_{m}^{P}}{D_{m}^{p}}\left(1+\sum_{n=1}^{\infty} \gamma_{m n}^{\prime} \cos \left(\varphi_{m 1 n}^{S}\right)\right)-\sum_{n=1}^{\infty} \gamma_{m n}^{\prime \prime} \cos \left(\varphi_{m 1 n}^{S}\right)}{D_{m}^{p} \sum_{n=1}^{\infty} \gamma_{m n}^{\prime} \bar{h}_{m 1 n}^{S} \sin \left(\varphi_{m 1 n}^{S}\right)+\theta_{m}-\sum_{n=1}^{\infty} \gamma_{m n}^{\prime \prime} \bar{h}_{m 1 n}^{S} \sin \left(\varphi_{m 1 n}^{S}\right)}=\frac{H_{v}^{\prime}(\omega)}{\rho_{m}^{P} A_{m}^{P} V_{m}^{P}}
$$

where $H_{v}^{\prime}(\omega)=-i \theta_{m} \frac{\frac{D_{m}^{P}}{D_{m}^{P^{\prime}}}\left(1+\sum_{n=1}^{\infty} \gamma_{m n}^{\prime} \cos \left(\varphi_{m 1 n}^{S}\right)\right)-\sum_{n=1}^{\infty} \gamma_{m n}^{\prime \prime} \cos \left(\varphi_{m 1 n}^{S}\right)}{\frac{D_{m}^{P}}{D_{m}^{P^{\prime}}} \sum_{n=1}^{\infty} \gamma_{m n}^{\prime} \bar{h}_{m 1 n}^{S} \sin \left(\varphi_{m 1 n}^{S}\right)+\theta_{m}-\sum_{n=1}^{\infty} \gamma_{m n}^{\prime \prime} \bar{h}_{m 1 n}^{S} \sin \left(\varphi_{m 1 n}^{S}\right)}$ is the dimensionless frequency response function of velocity corresponding to $H_{\mathcal{v}}(\omega)$.

\section{References}

1. Varghese, R.; Boominathan, A.; Banerjee, S. Stiffness and load sharing characteristics of piled raft foundations subjected to dynamic loads. Soil Dyn. Earthq. Eng. 2020, 133, 106177. [CrossRef]

2. Xu, Y.; Zeng, Z.; Wang, Z.; Yan, H. Seismic study of a widened and reconstructed long-span continuous steel truss bridge. Struct. Infrastruct. E 2020, 1, 1-11. [CrossRef] 
3. Gao, L.; Wang, K.H.; Xiao, S.; Li, Z.Y.; Wu, J.T. An analytical solution for excited pile vibrations with variable section impedance in the time domain and its engineering application. Comput. Geotech. 2016, 73, 170-178. [CrossRef]

4. Wu, W.B.; Liu, H.; Yang, X.Y.; Jiang, G.S.; EI Naggar, M.H.; Mei, G.X.; Liang, R.Z. New method to calculate the apparent phase velocity of open-ended pipe pile. Can. Geotech. J. 2020, 57, 127-138. [CrossRef]

5. Yuan, B.X.; Sun, M.; Xiong, L.; Luo, Q.Z.; Pradhan, S.P.; Li, H.Z. Investigation of 3D deformation of transparent soil around a laterally loaded pile based on a hydraulic gradient model test. J. Build. Eng. 2020, 28, 1-9. [CrossRef]

6. Luan, L.B.; Zheng, C.J.; Kouretzis, G.; Ding, X.M. Dynamic analysis of pile groups subjected to horizontal loads considering coupled pile-to-pile interaction. Comput. Geotech. 2020, 117, 103276. [CrossRef]

7. Miao, Y.; Shi, Y.; Zhuang, H.Y.; Wang, S.Y.; Liu, H.B.; Yu, X.B. Influence of seasonal frozen soil on near-surface shear wave velocity in Eastern Hokkaido. Geophys. Res. Lett. 2019, 46, 9497-9508. [CrossRef]

8. $\quad$ Liang, F.Y.; Zhao, M.Y.; Qin, C.R.; Jia, Y.J.; Wang, Z.W.; Yue, G.P. Centrifugal test of a road embankment built after new dredger fill on thick marine clay. Mar. Georesour. Geotech. 2020, 38, 114-121. [CrossRef]

9. Meng, K.; Cui, C.Y.; Li, H.J. An Ontology Framework for Pile Integrity Evaluation Based on Analytical Methodology. IEEE Access 2020, 8, 72158-72168. [CrossRef]

10. Shadlou, M.; Bhattacharya, S. Dynamic stiffness of pile in a layered continuum. Géotechnique 2014, 64, 303-319. [CrossRef]

11. Nogami, T.; Konagai, K. Dynamic Response of Vertically Loaded Nonlinear Pile Foundations. J. Geotech. Eng. 1987, 113, 147-160. [CrossRef]

12. Anoyatis, G.; Mylonakis, G. Dynamic Winkler modulus for axially loaded piles. Geotechnique 2012, 62, 521-536. [CrossRef]

13. Novak, M.; Nogami, T.; Aboulella, F. Dynamic soil reactions for plane strain case. J. Eng. Mech. ASCE 1978, 104, 953-959.

14. Manna, B.; Baidya, D.K. Vertical vibration of full-scale pile-Analytical and experimental study. J. Geotech. Geoenviron. 2009, 135, 1452-1461. [CrossRef]

15. Hu, C.B.; Wang, K.H.; Xie, K.H. Time domain axial response of dynamically loaded Pile in viscous damping soil layer. J. Vib. Eng. 2004, 17, 72-77. [CrossRef]

16. Wu, W.B.; Jiang, G.S.; Huang, S.G.; Leo, C.J. Vertical dynamic response of pile embedded in layered transversely isotropic soil. Math. Probl. Eng. 2014, 12, 1-12. [CrossRef]

17. Zheng, C.J.; Kouretzis, G.P.; Sloan, S.W.; Liu, H.; Ding, X.M. Vertical vibration of an elastic pile embedded in poroelastic soil. Soil Dyn. Earthq. Eng. 2015, 77, 171-181. [CrossRef]

18. Cai, Y.Q.; Hu, X.Q. Vertical vibrations of a rigid foundation embedded in a poroelastic half-space. J. Eng. Mech. 2010, 136, 390-398. [CrossRef]

19. Yang, X.; Pan, Y. Axisymmetrical analytical solution for vertical vibration of end-bearing pile in saturated viscoelastic soil layer. Appl. Math. Mech. 2010, 31, 193-204. [CrossRef]

20. Cui, C.Y.; Zhang, S.P.; David, C. Dynamic impedance of a floating pile embedded in poro-visco-elastic soils subjected to longitudinal harmonic loads. Geomech. Eng. 2018, 15, 793-803. [CrossRef]

21. Cui, C.Y.; Zhang, S.P.; Meng, K.; Xu, C.S.; Yang, G. An analytical solution for integrity detection of a floating pile embedded in saturated viscoelastic half space. Int. J. Distrib. Sens. Netw. 2018, 14, 1-8. [CrossRef]

22. Ghosh, S.K.; Cherstvy, A.G.; Grebenkov, D.S.; Metzler, R. Anomalous, non-gaussian tracer diffusion in crowded two-dimensional environments. New J. Phys. 2016, 18, 013027. [CrossRef]

23. Grima, R.; Schnell, S. A systematic investigation of the rate laws valid in intracellular environments. Biophys. Chemist. 2006, 124, 1-10. [CrossRef] [PubMed]

24. Novak, M.; Han, Y.C. Impedances of Soil Layer with Boundary Zone. J. Geotech. Eng. 1990, 116, 1008-1014. [CrossRef]

25. Liu, J.W.; Cui, N.; Zhu, N.; Han, B.; Liu, J. Investigation of cyclic pile-sand interface weakening mechanism based on large-scale CNS cyclic direct shear tests. Ocean Eng. 2019, 194, 106650. [CrossRef]

26. Novak, M.; Sheta, M. Approximate approach to contact problems of piles. In Proceedings of the Geotechnical Engineering Division, ASCE National Convention, New York, NY, USA, 30 October 1980; pp. 53-79.

27. Veletsos, A.S.; Dotson, K.W. Vertical and Torsional Vibration of Foundations in Inhomogeneous Media. J. Geotech. Eng. 1988, 114, 1002-1021. [CrossRef] 
28. Han, Y.C.; Sabin, G.C.W. Impedances for Radially Inhomogeneous Viscoelastic Soil Media. J. Eng. Mech. 1995, 121, 939-947. [CrossRef]

29. EI Naggar, M.H. Vertical and torsional soil reactions for radially inhomogeneous soil layer. Struct. Eng. Mech. 2000, 10, 299-312. [CrossRef]

30. Wang, K.H.; Yang, D.Y.; Zhang, Z.; Leo, C.J. A new approach for vertical impedance in radially inhomogeneous soil layer. Int. J. Numer. Anal. Meth. 2012, 36, 697-707. [CrossRef]

31. Yang, D.Y.; Wang, K.H.; Zhang, Z.; Leo, C.J. Vertical dynamic response of pile in a radially heterogeneous soil layer. Int. J. Numer. Anal. Meth. 2009, 33, 1039-1054. [CrossRef]

32. Li, Z.Y.; Wang, K.H.; Wu, W.B.; Leo, C.J. Vertical vibration of a large diameter pile embedded in inhomogeneous soil based on the Rayleigh-Love rod theory. J. Zhejiang Univ. Sci. A 2016, 17, 974-988. [CrossRef]

33. Nogami, T.; Novak, M. Soil-pile interaction in vertical vibration. Earthq. Eng. Struct. D 1976, 4, $277-293$. [CrossRef]

34. Militano, G.; Rajapakse, R.K.N.D. Dynamic response of a pile in a multi-layered soil to transient torsional and axial loading. Géotechnique 1999, 49, 91-109. [CrossRef]

35. Cui, C.Y.; Meng, K.; Wu, Y.J.; Chapman, D.; Liang, Z.M. Dynamic response of pipe pile embedded in layered visco-elastic media with radial inhomogeneity under vertical excitation. Geomech. Eng. 2018, 16, 609-618. [CrossRef]

36. Zheng, C.J.; Liu, H.L.; Kouretzis, G.P.; Sloan, S.W.; Ding, X.M. Vertical response of a thin-walled pipe pile embedded in viscoelastic soil to a transient point load with application to low-strain integrity testing. Comput. Geotech. 2015, 70, 50-59. [CrossRef]

(C) 2020 by the authors. Licensee MDPI, Basel, Switzerland. This article is an open access article distributed under the terms and conditions of the Creative Commons Attribution (CC BY) license (http://creativecommons.org/licenses/by/4.0/). 